\title{
Cerebral Vasospasm: A Review
}

\author{
J. Max Findlay, Joshua Nisar, Tim Darsaut
}

\begin{abstract}
Cerebral vasospasm is a prolonged but reversible narrowing of cerebral arteries beginning days after subarachnoid hemorrhage. Progression to cerebral ischemia is tied mostly to vasospasm severity, and its pathogenesis lies in artery encasement by blood clot, although the complex interactions between hematoma and surrounding structures are not fully understood. The delayed onset of vasospasm provides a potential opportunity for its prevention. It is disappointing that recent randomized, controlled trials did not demonstrate that the endothelin antagonist clazosentan, the cholesterol-lowering agent simvastatin, and the vasodilator magnesium sulfate improve patient outcome. Minimizing ischemia by avoiding inadequate blood volume and pressure, administering the calcium antagonist nimodipine, and intervention with balloon angioplasty, when necessary, constitutes current best management. Over the past two decades, our ability to manage vasospasm has led to a significant decline in patient morbidity and mortality from vasospasm, yet it still remains an important determinant of outcome after aneurysm rupture.
\end{abstract}

RÉSUMÉ: Vasospasme cérébral : revue du sujet. Le vasospasme cérébral consiste en un rétrécissement prolongé mais réversible d'une artère cérébrale débutant dans les jours suivant une hémorragie sous-arachnoïdienne (HSA). La progression vers l'ischémie cérébrale est liée surtout à la sévérité du vasospasme et sa pathogenèse est en lien avec le caillot formant une gaine autour de l'artère. Cependant, les interactions complexes entre l'hématome et les structures environnantes demeurent mal connues. Le délai entre l'HSA et le vasospasme fournit une occasion potentielle de prévention. Des essais contrôlés randomisés récents n'ont pas démontré que le clazosentan, un antagoniste de l'endothéline, la simvastatine, un hypocholestérolémiant, ou le sulfate de magnésium, un vasodilatateur, améliorent le résultat chez le patient. Actuellement, le meilleur traitement consiste à minimiser l'ischémie en s'assurant que le volume sanguin et la tension artérielle sont adéquats, en administrant de la nimodipine, un antagoniste du calcium, et en procédant à une angioplastie par ballonnet si nécessaire. Au cours des vingt dernières années, une diminution significative de la morbidité et de la mortalité due au vasospasme a été observée grâce à ces moyens de traitement. Cependant le vasospasme demeure un important déterminant de l'issue chez le patient après la rupture d'un anévrisme cérébral.

Keywords: cerebral ischemia, cerebral vasospasm, intracranial aneurysm, subarachnoid hemorrhage

doi:10.1017/cjn.2015.288

Can J Neurol Sci. 2016; 43: 15-32

Although cerebral vasospasm can rarely complicate traumatic subarachnoid hemorrhage (SAH), ruptured vascular malformations, hemorrhagic brain tumors, and indeed any condition that results in extensive bleeding into the subarachnoid space beneath the brain, in clinical practice vasospasm is by far most commonly associated with rupture of cerebral aneurysms within the basal subarachnoid cisterns. The pathogenesis, diagnosis, and management of vasospasm following cerebral aneurysm rupture are the subjects of this review.

Angiographic vasospasm is arterial narrowing seen on vascular imaging; it begins several days after SAH and peaks in severity about 1 week later. Clinical or symptomatic vasospasm is narrowing causing cerebral ischemia with corresponding symptoms and signs and is sometimes referred to as delayed ischemic neurological deficit. Progression to cerebral ischemia depends largely on the degree and distribution of arterial narrowing. Vasospasm can be focal or diffuse in distribution and mild, moderate, or severe in degree. Vasospasm affects only the intradural arteries and primarily, but not exclusively, arteries and arterioles located on the surface of the brain.

This review will touch upon a more recent suggestion that pathophysiological processes initiated by early brain injury related to aneurysm rupture, and separate from vessel narrowing and cerebral ischemia, may also contribute to delayed neurological deterioration. Determining the exact pathogenesis of this complex condition and developing a corresponding way of preventing it remain ongoing pursuits of neurosurgical research.

\section{EPIDEMiology OF VASOSPASM}

Angiographic vasospasm is common after rupture of an aneurysm, with an overall incidence of 50-90\%. ${ }^{1}$ Rough estimates are as follows: moderate or more severe vasospasm in at least one cerebral artery will develop in two-thirds of patients with ruptured aneurysms, half of these patients will become symptomatic as a result of ischemia, and a cerebral infarct will develop in about half of these symptomatic patients. An analysis of 2741 patients entered into SAH trials in the 1990s found that cerebral infarction had developed in $26 \%$ at 6 weeks, which correlated strongly with poorer outcome. ${ }^{2}$ Cerebral infarction was significantly associated with increasing patient age, worse neurological condition on admission, a history of hypertension or diabetes mellitus, larger aneurysm, induced hypertension as part of management, fever, and a diagnosis of symptomatic vasospasm. With modern SAH management routines, the combined risk for death and permanent disability from vasospasm alone has been reduced to less than $10 \%$, but it still remains one of the leading causes of preventable poor outcome after rupture of an aneurysm. ${ }^{3-5}$

From the University of Alberta Hospital - Medicine, Edmonton, Alberta, Canada (JMF, JN, TD).

Received March 25, 2015. Final Revisions Submitted July 8, 2015. Correspondence to: J. Max Findlay, University of Alberta Hospital, 2D1.02 WMC, 8440 112 Street, Edmonton, AB T6G 2B7. Email: max.findlay@albertahealthservices.ca. 


\section{Table 1: Modified Fisher scale and risk for vasospasm}

\begin{tabular}{l|l}
\hline 0 & No SAH or IVH: very low risk \\
\hline 1 & Focal or diffuse thin layer of SAH, no IVH: low risk \\
\hline 2 & Focal or diffuse thin layer of SAH, IVH present: moderate risk \\
\hline 3 & Focal or diffuse thick layer of SAH, no IVH: high risk \\
\hline 4 & Focal or diffuse thick layer of SAH, IVH present: very high risk \\
\hline
\end{tabular}

\section{Prediction of Vasospasm}

A large volume of persistent subarachnoid clot is the most important risk factor predictive of vasospasm after SAH. ${ }^{6,7}$ The original Fisher grading scale in which clot volume and distribution on admission computed tomography (CT) are related to risk for vasospasm has been modified and in one single-center study found to have greater predictive value for delayed ischemia and prognosis. ${ }^{8}$ This modified Fisher scale (Table 1) scores hemorrhage noted on CT from 0 to 4: 0 , no SAH or intraventricular hemorrhage (IVH) (very low risk for vasospasm); 1 , focal or diffuse thin layer of SAH, no IVH (low risk for vasospasm); 2, focal or diffuse thin layer of SAH, IVH present (moderate risk for vasospasm); 3, focal or diffuse thick layer of SAH, no IVH (high risk for vasospasm); and 4 , focal or diffuse thick layer of SAH, IVH present (highest risk for vasospasm). A slower rate of subarachnoid clot clearance has also been shown to be an independent predictor of vasospasm, although this is not an easy measurement in clinical practice. ${ }^{7}$

Other risk factors for the development of vasospasm have been identified, including a loss of consciousness at the time of rupture, poor neurological grade on admission, cigarette smoking, diabetes mellitus or hyperglycemia, and preexisting hypertension (Table 2). ${ }^{9-11}$ Premorbid left ventricular hypertrophy in either smokers or hypertensive patients was especially predictive of severe vasospasm in one large single-center series. ${ }^{12}$ Factors studied and found to have a possible relationship with risk for vasospasm include female gender, younger patient age, and aneurysm location. A recent single-center review found that distal anterior cerebral artery aneurysms had an unusually high incidence of symptomatic vasospasm. ${ }^{13}$ There has been a suggestion that Japanese people may be more susceptible to vasospasm. ${ }^{14}$ Cocaine use may also be an independent risk factor for vasospasm. ${ }^{15}$

Spontaneous perimesencephalic or prepontine SAH (sometimes referred to as "pretruncal" SAH) unassociated with

Table 2: Risk factors for vasospasm

\begin{tabular}{l}
\hline Thick subarachnoid clots \\
\hline Intraventricular hematoma \\
\hline Persistent subarachnoid clots (slow clearance) \\
\hline Poor neurological condition on admission \\
\hline Loss of consciousness associated with rupture \\
\hline History of cigarette smoking \\
\hline Preexisting hypertension \\
\hline Diabetes mellitus \\
\hline Cocaine use
\end{tabular}

aneurysm rupture is typically a low-volume hemorrhage that clears quickly with a low risk for the development of vasospasm. ${ }^{16}$ However, thick and persistent nonaneurysmal SAH of this type is associated with a risk for vasospasm.

There is some evidence that endovascular coiling, as opposed to microsurgical repair of ruptured aneurysms, is associated with a lower risk for the subsequent development of vasospasm, ${ }^{17-19}$ although a rigorous comparison has not yet been made. Intraoperative aneurysm rupture during surgical clipping was not found to correlate with increased vasospasm in a large singleinstitution review. ${ }^{20}$ Impaired cerebral autoregulation assessed by transcranial Doppler ultrasound techniques was found to be predictive of vasospasm when detected within the first few days following SAH in a recent single-center study. ${ }^{21}$

\section{Pathogenesis}

\section{Smooth Muscle Contraction}

Vasospasm is prolonged cerebral arterial constriction caused by vascular smooth muscle contraction. The hemoglobin released from subarachnoid blood clots triggers the entry and release of calcium and subsequent activation of calcium/calmodulindependent myosin light-chain kinase, which in turn leads to phosphorylation of the myosin light chain and induces actin and myosin cross-linkage and mechanical shortening (smooth muscle contraction). Such contraction requires adenosine triphosphate and calcium, and vascular smooth muscle relies more on extracellular than intracellular calcium stores, which enter through voltage-gated and receptor-operated calcium channels. Although myofilament activation depends on calcium and high-energy phosphates, chronic vasospasm, which ensues days later and lasts up to several weeks, does not. The contractile proteins protein kinase C, Rho kinase, and protein tyrosine kinase and their corresponding signal transduction pathways have been implicated in vasospasm models when their activation shifts the contractile mechanism toward increased shortening in the absence of high intracellular calcium levels. ${ }^{22,23}$ This contiguous and secondphase "chronic" vasospasm is less reversible with pharmacologic vasodilators both in animal models ${ }^{24}$ and in humans undergoing intra-arterial, pharmacologic vasodilation treatment.

Sustained vasoconstriction is associated not only with functional impairment of the vessel, but also with ultrastructural damage to the vascular wall layers, including vacuolization of endothelial cells and loss of tight junctions, breakage of the internal elastic lamina, and patchy myonecrosis in the tunica media. $^{25}$

\section{Endothelial Injury, Nitric Oxide, and Endothelin-1}

Autooxidation of the oxyhemoglobin contained in blood clots encasing cerebral arteries produces methemoglobin and superoxide anion radical, which in turn lead to lipid peroxidation. ${ }^{26,27}$ Harmful hydroxyl radicals and lipid peroxides permeate the vessel wall and injure endothelial and smooth muscle cells. ${ }^{28,29}$ Damage to the endothelium in particular is thought to play a key role in the establishment of vasospasm, either through the loss of endothelial nitric oxide (NO) synthesis, an important vasodilator and regulator of vascular tone, or through the overproduction of endothelin, a powerful vasoconstrictor peptide. ${ }^{30}$ These two endothelial-derived substances and the possible imbalance in their 
production after SAH are at the center of experimental vasospasm research at the present time.

Decreased availability of the simple molecule NO may contribute to the development of vasospasm; supporting this hypothesis are the following observations following experimental SAH in animals: (1) endothelial NO synthase (eNOS) dysfunction in vasospastic vessels, (2) NO scavenging by oxyhemoglobin, (3) reversal of vasospasm by NO donors, (4) disappearance of neuronal NO synthase activity from the adventitia of vasospastic vessels, and (5) decreased cerebrospinal fluid nitrite levels along with increased levels of asymmetric dimethyl-L-arginine, the endogenous inhibitor of NO synthase. ${ }^{31-39}$

Endothelin-1 (ET-1) is the predominant isoform of endothelin and has the greatest role in vasoconstriction. ET-1 is a 21-amino acid cleavage product of a 212 -amino acid peptide precursor, the final step mediated by endothelin-converting enzyme. It is released on the abluminal side of the tunica media, acts on neighboring vascular smooth muscle endothelial receptor $\mathrm{A}\left(\mathrm{ET}_{\mathrm{A}}\right)$ receptors, and causes profound and sustained vasoconstriction. ${ }^{40}$ ET-1 levels have been found to be elevated in the cerebrospinal fluid of patients in whom vasospasm and brain ischemia develop, ${ }^{41-43}$ and either inhibition of ET-1 production or antagonism of its effect has prevented vasospasm in animal models. ${ }^{40}$

It seems possible that derangements in either or both $\mathrm{NO}$ or ET-1 metabolism by cerebral vascular endothelium may play a critical role in the pathogenesis of vasospasm.

\section{Inflammation, Vessel Remodeling, and Vasospasm}

Although it has become clear that vasospasm is not a type of vasculitis, there is evidence that inflammatory mechanisms are activated after SAH and may therefore be involved in the development of vasospasm, possibly by contributing to vasocontraction or modifying the vessel wall extracellular matrix and smooth muscle cell phenotype - a process known as vascular "remodeling." 44 Inflammatory cytokines, ${ }^{45,46}$ intercellular adhesion molecules, ${ }^{47,48}$ and genetic upregulation of inflammatory, proliferative, and extracellular matrix-regulating genes ${ }^{49-51}$ have been examined. In humans, elevations of plasma complement C3a and soluble intercellular adhesion molecule-1 have been associated with poor outcome and the development of vasospasm, respectively ${ }^{52,53}$; increased intrathecal levels of the cytokine interleukin-6 predicted vasospasm in another small study. ${ }^{54}$

Although the precise pathogenesis of vasospasm is still the subject of investigation, a prolonged, biphasic vasoconstrictive process in which the second, chronic phase is mechanistically distinct from the first seems most consistent with what has been seen experimentally and in humans. It remains possible that additional processes, including inflammation, may contribute to the pathogenesis of this condition (Table 3).

Table 3: Theories on the pathogenesis of vasospasm

Prolonged, mechanistically distinct biphasic vasoconstriction:

Endothelin-1 overproduction (vasoconstrictor)

Nitric oxide underproduction (vasodilator)

Inflammation-mediated "remodeling" and narrowing of the arterial wall

Combined processes

\section{Early Brain Injury}

Vessel narrowing has traditionally been considered the major cause of delayed-onset neurological deterioration following $\mathrm{SAH}$, although it is clear that brain condition, the status of anatomical collateral blood supply, and systemic factors including circulating blood volume, blood pressure, and hematocrit importantly influence the impact of vasospasm on patients as it develops. The sometimes seen dissociation between location and severity of arterial narrowing and territories of cerebral ischemia ${ }^{55}$ and the failure of drugs targeting vasoconstriction to improve outcome ${ }^{56}$ has shifted attention to other possible but not yet recognized mechanisms behind delayed neurological deterioration after SAH. Early brain injury resulting from a spike in intracranial pressure and global cerebral ischemia at the time of aneurysm rupture may trigger a cascade of pathological processes, including inflammation, cortical spreading depression, capillary thrombosis, blood-brain barrier dysfunction, cerebral edema, and neuronal apoptosis. ${ }^{57-60}$ In combination with vasospasm, one or more of these processes may also underlie delayed neurological worsening after aneurysmal SAH.

\section{Clinical Features and Investigation}

\section{Symptoms, Signs, and Differential Diagnosis}

Coincident with its delayed onset, symptoms of ischemia resulting from cerebral vasospasm most commonly appear 1 week after aneurysm rupture but often occur later; accordingly, it is important to remain vigilant for this complication for at least 2 weeks after SAH. Regular and careful bedside examination remains the simplest and most effective means of detecting early ischemia in awake, examinable patients; one should concentrate on subtle findings such as diminished attention, changes in verbal output, or a new pronator drift of the upper extremity. Symptomatic vasospasm usually has a gradual onset, sometimes heralded by increased headache and either agitation or somnolence that is a change in patient behavior. It then follows a progressive course if untreated. A smaller group of patients will experience precipitous deterioration. ${ }^{61}$ Signs of symptomatic vasospasm are referable to the territory that has become ischemic and are most easily distinguished when they lateralize to a middle cerebral artery (MCA) territory with monoparesis or hemiparesis and, when the dominant hemisphere is affected, aphasia. Anterior cerebral artery vasospasm can be marked by leg weakness, sometimes bilateral in distribution, as well as confusion, drowsiness, poverty of speech, and eventually abulia. Vertebrobasilar vasospasm can cause more generalized neurological deterioration, with a reduced level of consciousness an early sign followed by any pattern of body weakness.

Vasospastic ischemia is difficult to detect in patients who remain in poor neurological condition following $\mathrm{SAH}$, so monitoring of comatose patients with ancillary techniques (discussed later) is particularly important.

Delayed neurological deterioration after aneurysmal SAH has several causes, including increased edema (surrounding intracerebral hematomas, surgical contusions, or infarcts), rebleeding of the aneurysm or an aneurysmal remnant, hydrocephalus, sepsis (including meningitis and ventriculitis), hyponatremia, hypoxia, and hypotension (Table 4). Any one (or a combination) of these conditions can magnify a preexisting neurological deficit and 


\section{Table 4: Causes of delayed deterioration after subarachnoid hemorrhage}

\begin{tabular}{l}
\hline Increased edema surrounding hematomas, contusions, or infarcts \\
\hline Rebleeding of aneurysms or aneurysmal remnant \\
\hline Hydrocephalus \\
\hline Infection, including ventriculitis \\
\hline Hyponatremia \\
\hline Hypoxemia \\
\hline Cortical spreading depression \\
\hline Cerebral vasospasm causing cerebral ischemia
\end{tabular}

therefore easily be mistaken for vasospasm. Care has to be taken not to automatically assume vasospasm and cerebral ischemia are the causes of delayed neurological deterioration in patients recovering from aneurysmal $\mathrm{SAH}$; a diligent search for other causes must be carried out.

On the other hand, previously mentioned in this review is a small subgroup of patients who suffer a delayed and often global decline in neurological status for which no underlying cause can be identified, including cerebral vasospasm. Early brain injury caused by an acute elevation in intracranial pressure and global cerebral ischemia at the time of aneurysm rupture may trigger a cascade of pathological processes, including cerebral inflammation, cortical spreading depolarization, microthrombosis, blood-brain barrier breakdown, cerebral edema, and apoptosis. ${ }^{23,57-60,62}$

\section{Diagnosis}

Diagnosis of symptomatic vasospasm requires that the other causes of delayed worsening listed earlier be ruled out with CT and appropriate laboratory investigations. If vasospasm remains the most likely cause of deterioration and treatment by induced hypertension reverses the deficit, the diagnosis can usually be assumed and additional testing is at the discretion of the treatment team. Failure to respond neurologically in this scenario, as well as evaluation of comatose patients, requires additional testing (Table 5). The following are most commonly used monitoring methods after SAH.

\section{Transcranial Doppler}

Transcranial Doppler (TCD) works on the principle that, as an artery narrows, blood flow velocity within it increases, causing a Doppler shift frequency between emitted and reflected waves. ${ }^{63}$ TCD is frequently used to monitor patients with SAH for increases in intracranial blood flow velocity suggestive of incipient vasospasm. TCD examinations are noninvasive, are carried out at the bedside, and can easily be performed on a daily basis providing patients have an adequate acoustic window in their temporal region through which to insonate. TCD is best used to detect proximal vasospasm because of segmental and diffuse increases in blood flow velocity in these vessels compared with more distal vessels. ${ }^{63}$ There is good general correlation between TCD velocities and vasospasm, with velocities in the MCA greater than $120 \mathrm{~cm} / \mathrm{second}$ being indicative of some degree of vasospasm and those greater than $200 \mathrm{~cm} / \mathrm{second}$ consistent with severe vasospasm. Because other factors such as blood pressure

\section{Table 5: Diagnosis of vasospasm}

\begin{tabular}{l}
$\begin{array}{c}\text { Detectable neurological worsening, deficits referable to the ischemic territory (paresis, } \\
\text { aphasia, abulia, decreased level of consciousness) }\end{array}$ \\
\hline Rule out all other causes of delayed deterioration \\
\hline $\begin{array}{l}\text { Pathologic increases in TCD velocities; there is a high probability of significant large- } \\
\text { artery vasospasm with velocities }>200 \mathrm{~cm} / \mathrm{second}\end{array}$ \\
\hline Pathologic reductions in CBF detected by \\
\hline Perfusion CT scanning \\
\hline Single-photon emission computed tomography \\
\hline Xenon-enhanced CT \\
\hline Thermal diffusion flowmetry \\
\hline Detection of cerebral ischemia or infarction by \\
\hline Diffusion-weighted magnetic resonance imaging \\
\hline Near-infrared spectroscopy \\
\hline Microdialysis \\
\hline Direct probe cerebral oximetry \\
\hline Jugular venous oxygen saturation \\
\hline Vascular imaging by \\
\hline Catheter-based angiography \\
\hline CT angiography \\
\hline
\end{tabular}

and overall cerebral blood flow (CBF) can influence velocity, distinguishing vasospastic from hyperemic increases in blood velocity has been reported to be facilitated by measuring cervical internal carotid artery velocity in addition to intracranial blood velocity. ${ }^{64} \mathrm{~A}$ "Lindegaard ratio" of $\mathrm{V}_{\mathrm{MCA}} / \mathrm{V}_{\text {ICA }}$ greater than 3 is consistent with vasospasm (hyperemia is associated with increased velocity in both the MCA and internal carotid artery, so the ratio is the same). ${ }^{63,64} \mathrm{~A}$ similar velocity ratio between the basilar artery and the extracranial vertebral artery has been proposed to improve the sensitivity and specificity of detecting basilar artery vasospasm. ${ }^{65}$

The clinical utility of TCD is best when MCA values are clearly low $(<120 \mathrm{~cm} / \mathrm{second})$ or very high $(>200 \mathrm{~cm} / \mathrm{second})$, and the respective negative and positive predictive values for significant angiographic vasospasm in the MCA trunk are close to $90 \% .^{66-68}$ For values in the intermediate range, additional maneuvers may improve its accuracy in detecting vasospasm, such as testing for hyperemic autoregulatory responses to transient, manual carotid compression, ${ }^{69,70}$ or combining the TCD information with CBF measurements. ${ }^{71}$ TCD does not reliably detect vasospasm in more peripheral branches, ${ }^{72}$ which may account for its failure to always correlate with perfusion deficits detected on CBF studies. ${ }^{73}$ Regular surveillance of SAH patients with TCD ultrasonography by skilled technicians is considered helpful in many neurosurgical units, but the results must be considered in the context of the individual patient along with all other information available.

\section{$\mathrm{CBF}$ and Perfusion}

Single-photon emission $\mathrm{CT}^{74}$ quantitative stable xenonenhanced $\mathrm{CT},{ }^{71}$ and positron emission tomography ${ }^{73}$ can be used to detect cerebral ischemia after $\mathrm{SAH}$, but none is a practical 
investigation that can be easily performed or repeated in critically ill patients. Magnetic resonance imaging to look for perfusion deficits $^{75}$ or ischemia on diffusion-weighted images ${ }^{76,77}$ has the same limitation.

Computed tomographic perfusion (CTP) or "perfusion CT scanning" has been used in patients with $\mathrm{SAH}^{78,79}$ and has rapidly gained popularity because of its ease of use, speed of image acquisition, and good correlation with digital subtraction angiography for angiographic vasospasm. ${ }^{80}$ It requires a contrast bolus to calculate regional CBF. Cerebral ischemia can be detected on the basis of side-to-side differences in perfusion or absolute thresholds values for $\mathrm{CBF}$ and mean transit time. CTP can provide early detection of reduced $\mathrm{CBF}$, prolongation of mean transit time (which is also indicative of ischemia), and the status of cerebral blood volume, which is normally maintained in penumbral brain, but markedly reduced in established infarcts. ${ }^{81}$ In a recent meta-analysis, the sensitivity of CTP in identifying patients with angiographic vasospasm was $74 \%$ and specificity $93 \% .^{82}$

Thermal diffusion flowmetry has been used as continuous bedside monitoring in SAH patients to detect vasospasm causing significant reductions in $\mathrm{CBF}^{83}$ Provided that the white matter location into which the thermal diffusion microprobe is inserted (usually the frontal lobe) is representative of the territory at risk, continuous measurement of CBF values could be useful in patients with high-grade SAH who cannot be assessed neurologically. It is an invasive monitor and because only a very small area of brain is being examined, sampling errors and falsenegative results are a concern.

\section{Near-Infrared Spectroscopy}

Near-infrared spectroscopy (NIRS) may prove to be a useful technology for simple, noninvasive bedside monitoring of cerebral ischemia following SAH. ${ }^{84-86}$ Probes are secured to the scalp with adhesive pads, allowing for prolonged and continuous monitoring. NIR light $(700-1000 \mathrm{~m})$ penetrates superficial layers (e.g. skin, subcutaneous fat, skull) and is either absorbed by chromophores (oxy- and deoxyhemoglobin) or scattered within the tissue. Measurement is based on the ability of light to penetrate the skull and to determine hemoglobin oxygenation according to the amount of light absorbed by hemoglobin. Unlike pulse oximetry (which uses a single sensor), cerebral oximetry with NIRS uses two photodetectors with each light source. The technology allows selective sampling of tissue beyond a specified depth beneath the skin. Near-field photodetection then can be subtracted from far-field detection to provide selective measurements of tissue oxygenation.

NIRS is a noninvasive and relatively low-cost optical technique for measuring tissue oxygen saturation, changes in hemoglobin volume, and, indirectly, CBF. NIRS detects ischemia through a decrease in cortical oxygen saturation and total hemoglobin. Time-resolved NIRS permits quantitative measurements of hemoglobin concentration, and in one pilot study was found more sensitive than TCD in the diagnosis of vasospasm. ${ }^{87}$ Verification from studies with larger sample sizes is required.

The limitation of NIRS is that the measurements of hemoglobin concentrations are averages, and sample only a small area of cerebral tissue. NIRS measures blood oxygenation predominantly in the venous compartment of a certain cortical region and the cerebrospinal fluid, the skull, and the other layers of the human head can interfere with the photon signals. ${ }^{88}$ NIRS probes can only be used on shaven or hairless parts of the head, most commonly the frontal regions. The positive feature of NIRS is its utility as a continuous bedside monitor for cortical blood oxygen saturation, total brain hemoglobin, oxyhemoglobin, and deoxyhemoglobin, which can be helpful in a multimodal approach to management.

\section{Microdialysis Monitoring}

Cerebral microdialysis catheters allow continuous bedside measurement of extracellular concentrations of glutamate, lactate, pyruvate, glucose, and glycerol in brain tissue, thereby screening for excitotoxic cell injury characterized by elevations in lactate with respect to glucose and pyruvate levels and an increase in the glycerol concentration. This somewhat demanding monitoring technique provides chemical information about a very small region of the brain, but it has been used, along with cerebral oximetry, to detect ischemia in patients with SAH. ${ }^{89-91}$ The markers with the most reliable prediction of ischemia are glutamate and lactate because these peak 24 hours before clinical ischemia followed by glycerol concentrations that peak 12 hours before clinical ischemia. Furthermore, raised lactate/glutamate ratios and lactate/pyruvate ratios are good prognostic indicators in $\mathrm{SAH}^{92}$ It should be noted that high lactate by itself does not indicate ischemia, but rather a hypermetabolic state that may show improved outcome.

\section{Brain Tissue Oxygen}

Direct cerebral oximetry can be carried out with a commercially available intraparenchymal brain probe (Licox Brain Tissue Oxygen Probe, Integra Neurosciences), which provides the partial pressure of oxygen in a continuous fashion. ${ }^{92}$ A level below $10-15 \mathrm{mmHg}$ is considered to represent hypoxia, but as with the microdialysis probe, direct cerebral oximetry is an invasive technique and samples only a minute territory of brain, as is the case with all parenchymal tissue probes.

\section{Vascular Imaging}

The most practical method of imaging large- and mediumsized cerebral arteries is digital subtraction angiography or highdefinition computed tomographic angiography. ${ }^{93}$ Magnetic resonance imaging is appealing in terms of the amount of information it can provide, but is difficult to carry out in critically ill patients. ${ }^{94}$

Computed tomographic angiography had a collective sensitivity and specificity of $80 \%$ and $93 \%$, respectively, in ten recent studies but failed to be as accurate as digital subtraction angiography because of artifacts from clips and coils. It has been recommended as an initial screening test. ${ }^{80}$ Catheter-based angiography is best in patients in whom balloon angioplasty is being considered.

Angiographic vasospasm is a concentric narrowing that can be focal, segmental, or diffuse. It is commonly graded as mild $(<25 \%)$, moderate ( $25 \%$ to $50 \%)$, or severe $(>50 \%)$ in comparison to baseline, prevasospasm imaging. "Early" vasospasm on admission angiography and within 48 hours of aneurysm rupture has been described in a small percentage of SAH patients, although without baseline angiography it is not clear how this diagnosis can be made accurately in all cases. ${ }^{95}$ Its detection has been associated with the development of cerebral infarction and poor outcome. 
Along with TCD and CBF measurements, properly timed and sometimes-repeated cerebral angiography is important in patients who are in poor neurological condition and in whom physical examination is difficult or inaccurate. If discovered, significant large-vessel vasospasm can then be treated.

\section{Prevention of Vasospasm and Cerebral Protection}

\section{General Measures: Fluid Management and Medical Treatment}

Patients have a tendency toward volume contraction in the acute stage of $\mathrm{SAH}^{96}$ and hypovolemia should be carefully avoided. It is not clear that a deliberate attempt to induce hypervolemia with volume expansion therapy is beneficial in terms of prevention of vasospasm or ischemia or even possible in patients with normal renal function. ${ }^{97-100}$ Patients should be hydrated with at least $3 \mathrm{~L}$ of isotonic fluids daily, and there is some evidence that additional colloid infusions (such as albumin) are beneficial. ${ }^{101}$ Some SAH patients experience excessive natriuresis known as "cerebral salt wasting" that is usually related to elevations in brain natriuretic peptide, and they are susceptible to the development of hyponatremia during this time. ${ }^{102}$ Hyponatremia may increase the risk for vasospasm $^{103}$ and is associated with cerebral infarction in poorgrade patients. ${ }^{104}$ Importantly, hyponatremia in the setting of SAH should not be treated with fluid restriction but rather with salt replacement in the form of normal or $3 \%$ hypertonic saline, combined with fludrocortisone (Florinef) administration $(0.3 \mathrm{mg} /$ day $)$ if the patient is experiencing vasospasm. ${ }^{102,105}$

Blood transfusion has been associated with a higher likelihood of both vasospasm and poor outcome in SAH patients, 8,106 suggesting that anemia is a marker for other factors that contribute to SAH-associated morbidity. The optimal hemoglobin concentration in patients with SAH in terms of hematocrit, blood viscosity, and oxygen delivery to the brain is not known with certainty, but is generally believed to be higher than $9 \mathrm{~g} / \mathrm{dl}$.

Systemic blood pressure should be maintained in the normotensive to slightly hypertensive range, provided that the aneurysm has been repaired. In patients with external ventricular drains, cerebral perfusion pressure $(\mathrm{CPP})$ is a more important parameter to monitor and maintain at $70 \mathrm{mmHg}$ or greater in poorer-grade patients. $^{107}$

Optimal ventilation and oxygenation, prevention of fever, maintaining euglycemia, good nutrition, and attention to the concentration of all electrolytes in addition to sodium are important in reducing the impact of vasospasm and delayed ischemia.

Nimodipine, administered orally or via a nasogastric tube, $60 \mathrm{mg}$ every 4 hours and continued for 3 weeks (for patients requiring that length of hospitalization), is standard treatment of patients with aneurysmal SAH because it was shown to have a statistically significant beneficial impact on clinical outcome, however modest. ${ }^{108}$ Nimodipine prevents increases in intracellular calcium by blocking dihydropyridine-sensitive (L-type) calcium channels, but its mechanism of effect in patients with SAH is unknown. It does not appear to reduce angiographically detectable vasospasm. It may work as a neuroprotective agent. Nimodipine can cause temporary depression of blood pressure, in which case the dose can be reduced and, if possible, given more frequently (i.e. $30 \mathrm{mg}$ every 2 hours) (Table 6).
Table 6: Prevention of vasospasm and cerebral protection

\begin{tabular}{l}
\hline General measures \\
\hline Endovascular coil repair of ruptured aneurysm versus microsurgical clipping \\
\hline Maintain euvolemia (at least $3 \mathrm{~L}$ of isotonic fluids daily) \\
\hline Prevent anemia (hemoglobin $<9 \mathrm{~g} / \mathrm{dl}$ ) \\
\hline Prevent hyponatremia \\
\hline Maintain normal to high systemic blood pressure \\
\hline Optimize ventilation and oxygenation \\
\hline Prevent high ICP (and maintain CPP) with external ventricular drainage as \\
\hline necessary \\
\hline Nimodipine, 60 mg by mouth or nasogastric tube every 4 hours \\
\hline Augmentation of subarachnoid clot clearance \\
\hline Clot lysis \\
\hline Lamina terminalis fenestration \\
\hline Lumbar CSF drainage \\
\hline "Head shaking" \\
\hline Combined treatment \\
\hline ICP, intracranial pressure.
\end{tabular}

\section{Investigational Preventive Treatments}

It is beyond the scope of this review to review the countless number of pharmacologic agents that have been tested in experimental models of SAH and vasospasm, many of which, by targeting a specific pathologic process, were intended to explore a particular pathogenetic theory for vasospasm. The following are preventive strategies that have been tested clinically.

\section{Prophylactic Balloon Angioplasty}

Based on the observation that angioplasty of canine carotid arteries prevented the development of vasospasm when the arteries were subsequently encased in blood clots, ${ }^{109}$ prophylactic transluminal balloon angioplasty was tested in a phase II multicenter, randomized trial. ${ }^{110} \mathrm{~A}$ total of 170 patients with thick subarachnoid clots were enrolled and 85 were randomized to undergo percutaneous transluminal balloon angioplasty within 96 hours of SAH; the major cerebral arteries targeted included the supraclinoid internal carotid artery, MCA M1 segments, and the basilar artery. Although there was a trend toward reduced vasospasm in the patients treated prophylactically by percutaneous transluminal balloon angioplasty, outcome was no different from that in the control group, and the safety of this treatment was questionable; four patients had a procedure-related vessel perforation, three of whom died.

\section{Clot Clearance}

Intracisternal thrombolysis with either recombinant tissue plasminogen activator or urokinase speeds clearance of subarachnoid clots, and there is evidence that this is associated with prevention of vasospasm and less cerebral ischemia (Figures 1 and 2). ${ }^{111}$ However compelling the rationale of intrathecal thrombolysis, safety concerns about introducing a 

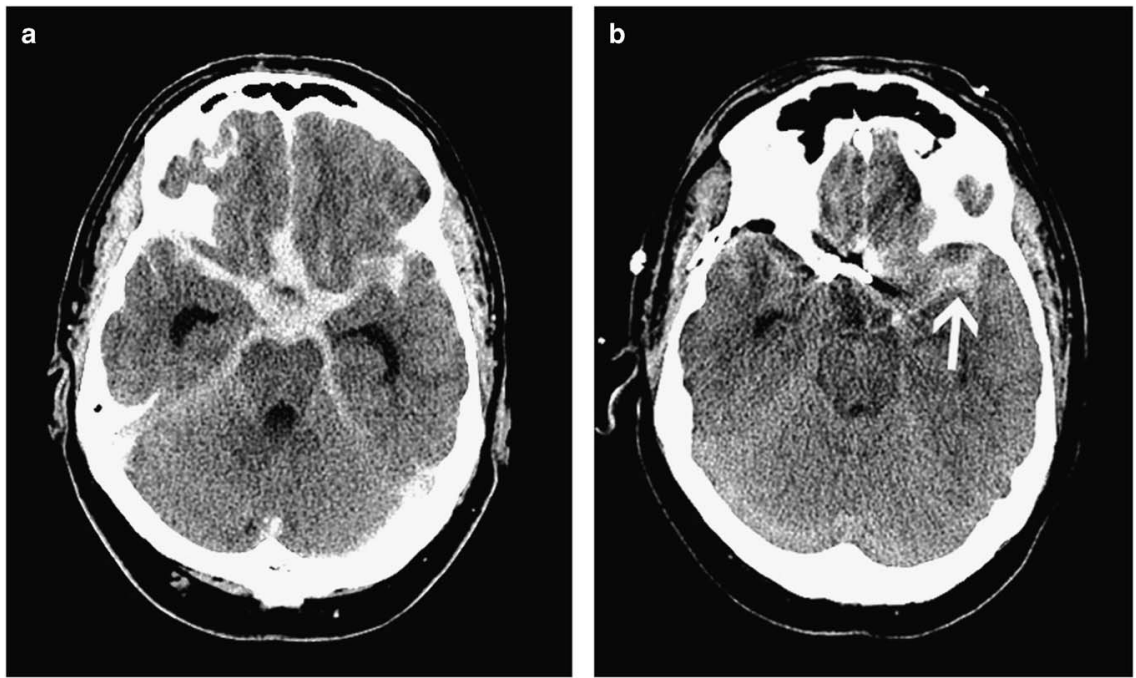

Figure 1: This 55-year-old man suffered a sudden headache with vomiting during coitus and on arrival to hospital several hours later was responsive with a normal neurological examination. CT scanning showed diffuse, symmetric, and thick SAH (A, Fisher grade 4, very high risk of vasospasm) as well as hydrocephalus. Immediately following clip repair of his anterior communicating artery aneurysm, $10 \mathrm{mg}$ of recombinant tissue plasminogen activator (rt-PA) was administered into the basal cisterns. The following morning, CT scanning showed good clearance of the clot from the central basal cisterns, with some residual hematoma in the left Sylvian fissure (B, arrow; also see Figure 2).

thrombolytic agent into the subarachnoid space in a recently injured brain has precluded wide acceptance of this approach. Kinetic therapy in the form of "head shaking" with cisternal thrombolysis, ${ }^{12}$ or intraventricular fibrinolysis, ${ }^{113}$ or with lumboventricular lavage ${ }^{114}$ has been reported to be beneficial in single-center studies, as has simple lumbar drainage. ${ }^{115,116}$
Finally, one report has suggested that fenestration of the lamina terminalis at the time of aneurysm clipping reduces the incidence of not just subsequent hydrocephalus, but also vasospasm from $55 \%$ to $30 \%$ in patients with thick subarachnoid clots, the proposed mechanism being increased cerebrospinal fluid flow and clot clearance in the basal subarachnoid cisterns. ${ }^{117}$
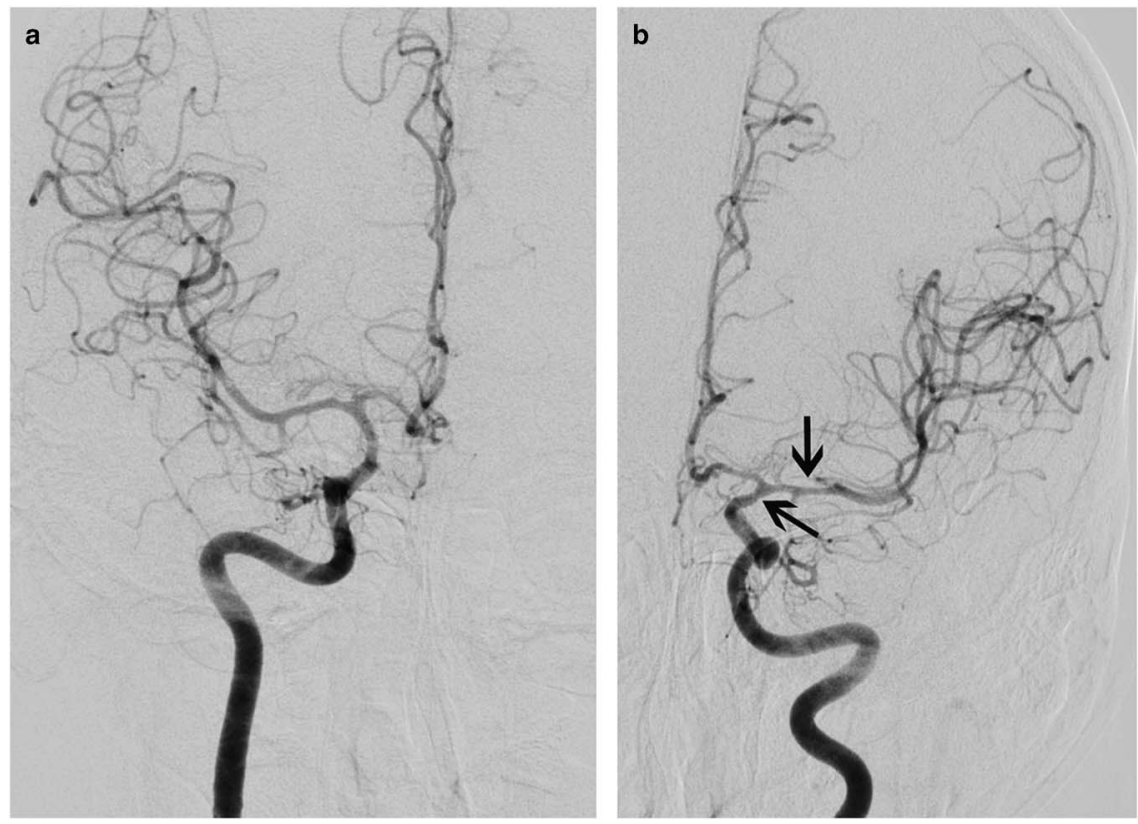

Figure 2: The patient did not experience delayed ischemia, and cerebral angiography 8 days later showed only mild vasospasm of the left supraclinoid internal carotid and proximal middle cerebral arteries $(A$, anteroposterior projection of the right internal carotid artery injection; $B$, anteroposterior projection of the left internal carotid artery injection, with arrows). 


\section{Intrathecal Vasodilators}

Prolonged-release nicardipine implants placed in the subarachnoid space of patients with thick clots and undergoing surgical clipping appeared to significantly prevent vasospasm and ischemia in a single-center, nonrandomized cohort study ${ }^{118}$; these results are similar to those in a previous study in which papaverine pellets were used. $^{119}$ A randomized, placebo-controlled phase IIa trial of prolonged-release nicardipine surgical implants found that nicardipine reduced the incidence of vasospasm and delayed ischemic deficits as well as improving clinical outcome after severe SAH and aneurysm clipping. ${ }^{120}$ However promising, it is unclear how this form of nicardipine treatment could be applied to patients undergoing endovascular coiling of ruptured aneurysms.

There is interest in administering nimodipine in a slow-release gel to patients via an external ventricular drain to act as a direct vasodilator and possible neuroprotectant, and a pilot study including patients with aneurysms either clipped or coiled is under way (Edge Therapeutics EG-01-1962-02 Nimodipine Microparticles to Enhance Recovery While reducing Toxicity after Subarachnoid Hemorrhage study).

\section{Magnesium}

Magnesium sulfate $\left(\mathrm{MgSO}_{4}\right)$ has neuroprotective and vasodilatory properties and has therefore been tested for the prevention of vasospasm and ischemia in patients with $\mathrm{SAH}$. One early study found no benefit from intravenous $\mathrm{MgSO}_{4}$ infusions, ${ }^{121}$ another showed various trends toward benefit, ${ }^{122}$ and a third suggested efficacy equivalent to nimodipine in preventing ischemic damage. ${ }^{123}$ Several additional trials have since been completed, including several large, international, and multicenter phase 3 randomized controlled studies, Intravenous Magnesium Sulfate for Aneurysmal Subarachnoid Hemorrhage (IMASH; 327 patents enrolled) and IMASH-2 (1204 patents enrolled). ${ }^{124,125}$ Those large trials, as well as a recent meta-analysis, found that intravenous magnesium $\left(20 \mathrm{mmol} \mathrm{MgSO}_{4}\right.$ administered over 30 minutes followed by a continuous infusion of $80 \mathrm{mmol} \mathrm{MgSO}_{4}$ per day for 14 days) did not increase the probability of good neurological outcome or decrease the risks of cerebral infarction, radiographic vasospasm, or mortality. ${ }^{126}$ There is no evidence at this time to support the use of intravenous magnesium sulfate following aneurysmal SAH.

\section{Endothelin Receptor Antagonists}

As discussed earlier, ET-1 overproduction from cerebral endothelial cells damaged by $\mathrm{SAH}$ is one of the leading theories behind the pathogenesis of cerebral vasospasm. The $\mathrm{ET}_{\mathrm{A} / \mathrm{B}}$ receptor antagonist TAK-044 was found to reduce delayed ischemia with an acceptable safety profile in a phase II randomized controlled trial, but with no apparent effect on outcome. ${ }^{127}$ The $\mathrm{ET}_{\mathrm{A}}$ receptor antagonist clazosentan, which showed promising results in a multicenter phase IIa study, ${ }^{128}$ has now been studied in a randomized, double-blind, placebo-controlled, phase II dose-finding trial (Clazosenatan to Overcome Neurological iSChemia and Infarct OccUrring after Subarachnoid hemorrhage [CONSCIOUS-1]). ${ }^{129}$ Treatment with either 1,5 , or $15 \mathrm{mg} /$ hour of intravenous clazosentan was started within 56 hours of SAH and continued up to 14 days. The primary endpoint, moderate to severe angiographic vasospasm, was significantly reduced in a dose-dependent fashion from $66 \%$ in the placebo group to $23 \%$ in the $15-\mathrm{mg} /$ hour clazosentan group (risk reduction, $65 \%$; $95 \%$ confidence interval, $47 \%$ to $78 \% ; \mathrm{p}<0.0001)$. There was no clear effect on infarction or outcome, and clazosentan was associated with increased rates of pulmonary edema, hypotension, and anemia. CONSCIOUS-2 was a multicenter placebo-controlled phase III study examining the effect of $5 \mathrm{mg} /$ hour clazosentan, given for up to 14 days after aneurysm clipping $(\mathrm{n}=768)$ versus placebo $(\mathrm{n}=389) .{ }^{130}$ The 6-week primary composite endpoint included all-cause mortality, vasospasm-related new cerebral infarcts, delayed ischemic neurological deficit because of vasospasm, and initiation of rescue therapy for vasospasm. The main 12-week secondary endpoint was functional outcome using the extended Glasgow outcome scale. Clazosentan at this dose had no significant effect on mortality, vasospasm-related morbidity, or functional outcome. Lung complications, anemia, and hypotension were more common with clazosentan. Subgroup analysis indicated that clazosentan did reduce vasospasm-related morbidity in poor-grade patients and those with diffuse, thick SAH at baseline, without improving functional outcome in those same groups. CONSCIOUS-3 was a similar phase III trial of clazosentan in patients whose aneurysms were secured by endovascular coiling as opposed to clipping, but in additional to the dose of $5 \mathrm{mg} /$ hour included a $15-\mathrm{mg} /$ hour treatment group. $^{131}$ This study was halted prematurely after CONSCIOUS-2 results were known. Again, no overall benefit from treatment with clazosentan was seen in terms of functional outcome, although the higher dose did significantly reduce vasospasm-related morbidity/all-cause mortality.

It is unclear why clazosentan, which had been shown to reduce vasospastic arterial narrowing, did not also reduce the incidence of poor outcome, but the authors suggest it could be due to methodological problems, inadequate sample size, insensitivity of clinical outcome measures, imbalance in the use of rescue therapy, or because mechanisms other than vasospasm (and upon which the drug has no effect) also contribute to poor outcome in an important way.

\section{Statins}

Statin agents inhibit 3-hydroxyl-3-methylglutaryl coenzyme A reductase, which is the rate-limiting enzyme in the mevalonate pathway of cholesterol synthesis. In addition to their hypolipidemic activity of lowering cholesterol levels, they have other salutary effects on the cardiovascular system, including improving endothelial function, modulating inflammatory responses, maintaining the stability of atherosclerotic plaque, and preventing thrombus formation. Perhaps important as they relate to $\mathrm{SAH}$, statins also improve CBF by upregulation of eNOS. Statins increase NO biosynthesis and bioavailability, which gave them great potential for vasospasm prophylaxis in the setting of SAH. ${ }^{132}$

In a pilot randomized clinical trial, simvastatin $(80 \mathrm{mg})$ given once daily for 14 days appeared to decrease the incidence of radiographic vasospasm and delayed ischemia. ${ }^{133}$ Reduced vasospasm and cerebral infarction were also found in several cohort studies comparing SAH outcomes in statin users and nonusers at the time of hospital admission. ${ }^{134,135} \mathrm{~A}$ phase II placebo-controlled trial of 80 patients randomized to receive either placebo or $40 \mathrm{mg}$ of oral pravastatin for up to 14 days found that statin use reduced vasospasm and severe vasospasm by $32 \%$ 
and $42 \%$, respectively, and reduced vasospastic infarcts and mortality by $83 \%$ and $75 \%$, respectively (all significant p values). ${ }^{136}$ The improvement in early outcome proved durable at 6 months. ${ }^{137}$ A small single-center randomized controlled trial of simvastatin $80 \mathrm{mg}$ once daily versus placebo found a significant reduction in cholesterol and low-density lipoprotein in the statintreated patients, but not in any other parameter including delayed cerebral ischemia and poor outcome. ${ }^{138}$ Another cohort study indicated that although the cholesterol-lowering agent atorvastatin reduced the incidence of vasospastic infarction seen on CT scanning, it did not improve clinical outcome. ${ }^{139}$ A meta-analysis of six randomized controlled statin trials found that, although delayed ischemic deficits were less common in the statin-treated patients, there was no overall significant reduction in poor neurological outcome. ${ }^{140}$ The international, randomized, and double-blind trial Simvastatin in Aneurysmal Subarachnoid Hemorrhage, which recruited 803 patients until February 2013, failed to detect any benefit in the use of simvastatin, $40 \mathrm{mg}$ per day, started within 96 hours of ictus then for up to 3 weeks, for either short- or long-term outcomes. ${ }^{141}$ High-dose simvastatin ( $80 \mathrm{mg}$ per day for 3 weeks) was compared with $40 \mathrm{mg}$ per day for 3 weeks in a randomized, controlled, double-blinded clinical trial that recruited 255 patients. ${ }^{142}$ No difference was seen between the high- and low-dose groups in the incidence of delayed ischemic deficits or clinical outcome. At present, it would appear that patients with $\mathrm{SAH}$ do not benefit from the addition of statins during the acute stage.

\section{Tirilazad Mesylate}

Tirilazad, an inhibitor of iron-dependent lipid peroxidation and free radical scavenger, was tested in a series of large-scale randomized, controlled trials and became licensed for use in several countries, although not in North America. An analysis of all tirilazad results showed decreased mortality associated with treatment, but other good-outcome endpoints did not show benefit except in a post hoc analysis of poor-grade patients. ${ }^{143}$ Because of gender-specific pharmacokinetics, higher dosages were necessary in women, who appeared to benefit less than men.

\section{Reversal of VAsospasm and Cerebral Ischemia: Rescue TreatMenT}

Augmentation of $\mathrm{CBF}$ through and via collaterals around vasospastic vessels by elevating systemic blood volume and pressure can reverse cerebral ischemia, and either pharmacologic or balloon dilation of narrowed arteries can reverse vasospasm itself. When and how these two "reversal" or "rescue" treatments should be implemented and combined is subject to some variation.

\section{Triple-H Therapy: Hypervolemia, Hypertension, and Hemodilution}

This combination is intended to improve cardiac output, increase CPP, and optimize hemorheology for oxygen transport. A degree of hemodilution accompanies any deliberate volume expansion, and reduced viscosity may contribute to an improvement in oxygen delivery, provided that the hematocrit (i.e. the oxygen-carrying capacity) does not fall below 30 and the hemoglobin concentration is maintained higher than $9 \mathrm{~g} / \mathrm{dl}$.
When symptomatic vasospasm is diagnosed or strongly suspected, hemodynamic treatment can commence by additional volume expansion with an isotonic crystalloid infusion, which in euvolemic patients raises $\mathrm{CBF}$ in vasospastic territories without a significant change in cardiac indices. ${ }^{144} \mathrm{~A}$ replete intravascular volume beyond which additional expansion is probably of no further benefit corresponds to a central venous pressure between 8 and $10 \mathrm{mmHg}$ or a pulmonary capillary wedge pressure in the range of 14 to $16 \mathrm{mmHg}$. Unless patients have a complicated cardiopulmonary status (because of myocardial infarction, heart failure, or pulmonary edema, for example), a pulmonary artery catheter is unnecessary. ${ }^{145,146}$ There is evidence that aggressive hemodynamic monitoring with a transpulmonary thermodilution monitoring system (PiCCO Plus, Pulsion Medical Systems SE, Feldkirchen, Germany) that measures cardiac output, global end-diastolic volume index, extravascular lung water index, pulmonary vascular permeability index, and systemic vascular resistance index, and then administration of fluid therapy directed by these parameters to optimize hemodynamic status, is beneficial in poor-grade patients. 147 "Early goal-directed fluid therapy" using PiCCO monitoring was associated with significantly less delayed cerebral ischemia and better functional outcome compared with standard fluid therapy (guided by fluid balance and a central venous catheter), although the difference was only seen in poor-grade patients. ${ }^{148}$ Induced hypertension is more effective than aggressive hypervolemia in improving cerebral oxygenation in patients with vasospasm and has fewer complications. ${ }^{149}$ Provided that the ruptured aneurysm has been repaired, symptomatic vasospasm should be treated by the administration of a vasopressor, the most commonly used being phenylephrine or norepinephrine. $^{150}$ The more purely $\alpha$-agonist vasopressors, norepinephrine (titrated to a maximum dose of $20 \mu \mathrm{g} / \mathrm{kg}$ per minute) and phenylephrine (titrated to a maximum dose of $180 \mu \mathrm{g} / \mathrm{kg}$ per minute), or a combination of the two, should be commenced promptly. Dobutamine or dopamine can be considered, which at low to moderate doses have mainly $\beta$-agonist, inotropic effects. Another cardiac inotrope, milrinone, has also been used after SAH. ${ }^{151}$ Blood pressure rises with elevations in cardiac output, which increases CPP. However, if a prompt blood pressure response does not occur with an inotrope (i.e. to dopamine administered at 10 to $15 \mu \mathrm{g} / \mathrm{kg}$ per minute), either epinephrine or norepinephrine should be added. At high doses, dopamine also causes $\alpha$-adrenergic agonism; however, it is accompanied by unwanted tachycardia because of $\beta_{2}$ receptor activity, which norepinephrine does not possess.

The key aspect of treatment is rapid elevation of blood pressure, regardless of the agent chosen. Systolic blood pressure of $200 \mathrm{mmHg}$ or higher or CPP greater than $80 \mathrm{mmHg}$ is sometimes required, but if ischemic signs persist at systolic pressures in this range or higher, hypertensive treatment should be considered to have failed. Blood pressure elevations this extreme might also aggravate cerebral ischemic cerebral edema leading to dangerous elevations in intracranial pressure.

It should be noted that hypertension and hypervolemia do not seem to increase the risk for hemorrhage from unsecured, unruptured aneurysms in the acute setting or in their short-term natural history. $^{152}$

The significant risks of triple-H therapy are cardiac failure and infarction, pulmonary edema, the complications associated with either central venous catheter or pulmonary artery catheter 
placement, and possibly cerebral edema and raised intracranial pressure. ${ }^{153-155}$ Risks are greatest in the elderly and in patients with intrinsic, preexisting cardiopulmonary disease.

\section{Intra-aortic Balloon Counterpulsation}

Originally designed for the management of cardiogenic shock, placement of a transfemoral aortic balloon that inflates on aortic valve closure with each cardiac cycle and augments diastolic flow proximally to the coronary and cranial arteries and distally to the peripheral circulation has been reported to be feasible and effective in patients with combined severe vasospasm and cardiac failure. ${ }^{156,157}$ Administration of intra-aortic balloon counterpulsation as vasospasm prophylaxis for patients at high risk of vasospasm but normal cardiac function did not confer any clinical benefit in a small, single-center randomized controlled trial. ${ }^{158}$

\section{Endovascular Reversal of Vasospasm}

If the hemodynamic goals of triple-H therapy are not easily met in a patient with persistent signs of cerebral ischemia, if the signs do not reverse within several hours of hypertension induced into the target range, or if a patient has a fragile cardiopulmonary status, it is appropriate to proceed directly to endovascular treatment of vasospasm. It is important to first rule out a large cerebral infarct with CT because dilation therapy is both futile and dangerous in this situation.

In the setting of symptomatic vasospasm, angiography will show which segments of the intracranial vasculature are affected, but this must be correlated with clinical examination and TCD results. The internal carotid and basilar arteries can usually be safely dilated using currently available endovascular balloons, as can the first (M1) segment of the MCA. Mechanical balloon angioplasty is preferably performed within 2 hours of symptom onset for best results. ${ }^{159}$ Balloon catheters are selected to match the baseline, normal diameter of the arterial segment in vasospasm. Choosing an oversized balloon can result in catastrophic vessel rupture, so it is important to examine the patient's prior, prevasospastic imaging, and in part to ensure that a hypoplastic artery is not mistaken for vasospasm. Once the balloon is selected, the wire and then balloon are navigated across the site of stenosis. When the narrowed segment is long, it is sometimes simplest to place the balloon distally; following balloon inflation, the balloon is deflated, pulled proximally, and reinflated until the entire segment has been dilated.

The efficacy of mechanical balloon angioplasty was nearly $100 \%$ in a recent series, and associated with a complication rate of only $1 \% .^{160}$ These reported results are significantly better than older series, where efficacy ranged from 11 to $93 \%$, associated clinical improvement rate of 328/530 (62\%), and a major complication rate of $5 \%$, including vessel rupture in $1.1 \%{ }^{161}$

Canine models of vasospasm have shown that the results of dilation are durable for up to 3 weeks. ${ }^{162,163}$ This mirrors clinical experience, in which balloon angioplasty is typically effective for the remainder of the vasospasm episode and patients rarely require repeat balloon dilation. ${ }^{164-166}$ However, mechanical dilation is only effective over the segment of the artery where the balloon was inflated, and it is possible to develop symptomatic vasospasm later in an adjacent, usually distal arterial segment. Although very uncommon, reintervention can occasionally be required for balloon dilation of the same vasospastic segment ${ }^{167}$; much more commonly, repeat treatment is required for adjacent arterial segments. 168,169

Although balloon angioplasty is usually reserved for larger ( $\geq 2.0 \mathrm{~mm}$ diameter) vessels, there is one recent report of $175 \mathrm{safe}$ angioplasties in distal vessels without procedure-related symptomatic complications. ${ }^{168}$ Those authors recommend using a calibrated balloon to decrease the risk of vessel rupture.

Further technical pitfalls to avoid include balloon inflation next to a fresh coil mass or recently placed clips because the expansion of the balloon may disrupt the coils or clips, with potential hemorrhagic or ischemic consequences.

For vasospasm affecting more distal vessels, where the operator judges that the risks of angioplasty are too great, local delivery of vasodilators might help establish sufficient vessel caliber to prevent infarction. The use of local intra-arterial milrinone in this setting is currently of interest. ${ }^{170,171}$ Milrinone, a selective phosphodiesterase III inhibitor, can be administered through a simple microcatheter or a deflated dual-lumen balloon catheter placed proximal to the spastic territory. Hemodynamic instability can be encountered, so slow infusions (over 30-40 minutes) are preferable, with close attention paid to blood pressure and heart rate. Other intra-arterial vasodilators such as papaverine, nifedipine, verapamil, and nimodipine have been also used for vasospasm in a similar manner, with inconsistent results. Most important, in our opinion, is that when distal vasospasm beyond the reach of the balloon catheter is seen at the end of the intervention it is important to maintain triple- $\mathrm{H}$ treatment afterwards and in particular induced hypertension, until the vasospasm period is over (Figures 3 and 4).

\section{Intravenous Milrinone and Other Reversal Therapies}

Milrinone is a selective phosphodiesterase III inhibitor affecting cyclic adenosine monophosphate pathways, with both inotropic and vasodilatory properties. ${ }^{172}$ There have been scattered reports of milrinone's potential positive effect on both experimental and clinical vasospasm when administered either into the subarachnoid cisterns, intravenously, or intra-arterially. ${ }^{170,173-175}$ A retrospective case series consisting of 88 patients with symptomatic vasospasm treated with intravenous milrinone between 1999 and 2006 has been reported. ${ }^{176}$ The "Montreal Neurological Hospital protocol" consists of a milrinone $0.1-0.2 \mathrm{mg} / \mathrm{kg}$ intravenous bolus followed by a $0.75 \mathrm{mcg} / \mathrm{kg} /$ minute infusion, combined with optimal hydration and correction of any electrolyte or glucose abnormalities. If the patient failed to improve after 30 minutes, the infusion was increased to $1.25 \mathrm{mcg} / \mathrm{kg} / \mathrm{minute}$, and vasopressor infusions were begun to either restore or achieve blood pressure targets when necessary (68\% of patients). Milrinone infusions were continued for a mean of 10 days and were considered by the authors as safe. Only one patient received intra-arterial milrinone and no angioplasties were carried out in this large case series. Roughly $40 \%$ of patients demonstrated vasospasm-related infarcts on CT scanning. This experimental treatment strategy with intravenous milrinone has not yet been reported in a controlled study, and it is premature at this time to consider it a vasospasm treatment "protocol."

In patients with severe and medically refractory vasospasm, sodium nitroprusside, an NO donor, has been administered into the lateral ventricles, either as single injections or as a continuous infusion via a ventriculostomy catheter, but the results have not 

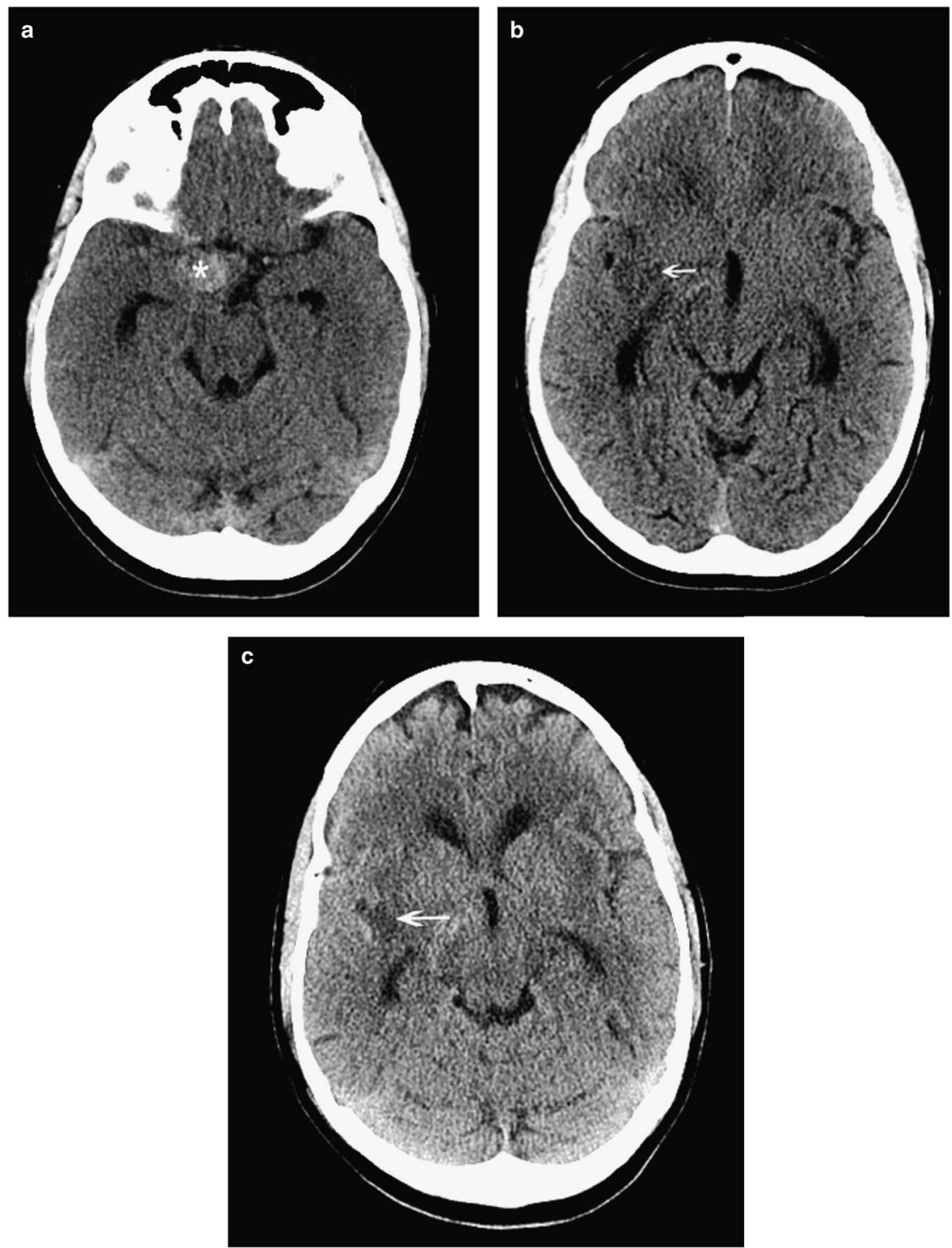

Figure 3: This 56-year-old woman was diagnosed with subarachnoid hemorrhage 10 days following her thunderclap headache, and CT was finally done for persistent headache and new-onset left-sided numbness and weakness. CT scanning showed a spherical hyperdensity in the right basal cisterns (A, asterisk), which was a large aneurysm as well as ischemic hypodensities in the left frontotemporal peri-insular brain tissue $(B, C$; arrows). Ten days following rupture, the subarachnoid blood had largely cleared from the subarachnoid cisterns (see Figure 4).

been consistent or promising. ${ }^{177,178}$ Cervical sympathetic blockade with regional anesthesia appeared to result in improvement of mild to moderate symptoms of vasospasm, but without reversal of angiographic vasospasm. ${ }^{179}$

\section{A Practical Approach to the Prevention and Treatment OF VASOSPASM}

Patients should be kept well-hydrated with isotonic crystalloid (at least $3 \mathrm{~L} /$ day, combined), intracranial pressure is kept normal with the liberal use of external ventricular drainage, and CPP is optimized to levels higher than $70 \mathrm{mmHg}$. No attempt need be made to control mild or moderate hypertension (Table 7). Daily TCD examinations are valuable to screen for developing vasospasm, and values in excess of $200 \mathrm{~cm} / \mathrm{second}$ in the MCA are indicative of significant angiographic vasospasm in that vessel. Regular clinical assessment to search for subtle changes in mentation, verbal output, and arm and hand control is critical. Obtunded or sedated patients being ventilated should be considered for direct vascular imaging (computed tomographic angiography is useful except for examination of the arteries immediately adjacent to the clip[s] or coils) on postSAH day 5 and then again several days later if considered necessary. 

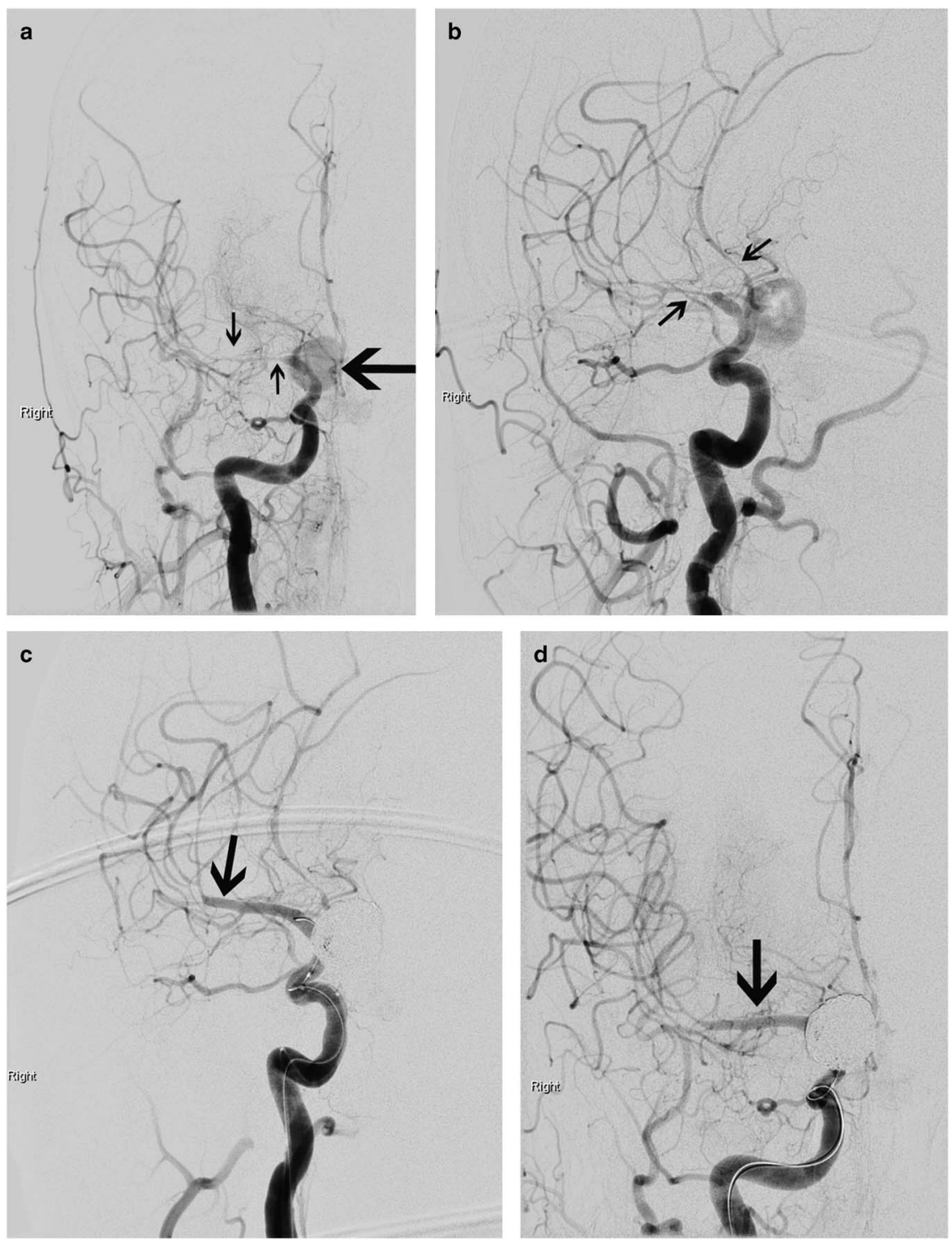

Figure 4: By the time of catheter angiography several hours later, the patient's entire left side had become paralyzed. Angiography showed a large, sluggishly opacifying, right-sided posterior communicating artery aneurysm (large arrow, A), critical right middle cerebral artery vasospasm, and narrowing of the anterior cerebral arteries as well (A, B; small arrows). The aneurysm was occluded with coils and then the M1 segment of the middle cerebral artery underwent balloon angioplasty $(C, D$; arrows) followed by induced hypertension for persistent vasospasm of the more distal middle cerebral as well as anterior cerebral arteries. She recovered spontaneous movement on her left side promptly, and follow-up CT scanning showed no extension of her infarction. She went on to make a good recovery over 6 months.

All patients should receive nimodipine, $60 \mathrm{mg}$ every 4 hours by mouth or via a nasogastric tube for 21 days or as long as they remain in the hospital, phenytoin should be avoided unless the patient has a documented seizure, and corticosteroids are not recommended. Every effort should be made to avoid hyponatremia, fever, and hypoxia, and patients should be fed as soon as possible.

Symptomatic vasospasm and moderate to severe angiographic vasospasm in comatose patients should be treated by infusion of a vasopressor. For most patients, central venous catheters are preferable to pulmonary artery catheters, and euvolemia or slight hypervolemia should be ensured. If signs do not respond quickly and completely or a target blood pressure and CPP are difficult to reach, it is recommended to move directly to endovascular treatment with angioplasty for all reachable, symptomatic segments of vasospasm. A CT scan should be performed first to rule out a large, established infarction or a new hemorrhage. In general, one should not wait until medical treatment of symptomatic vasospasm has utterly failed over a period of hours before initiating endovascular treatment, because under these circumstances angioplasty is more often inconvenient, dangerous, and unsuccessful. 


\section{Table 7: Vasospasm management}

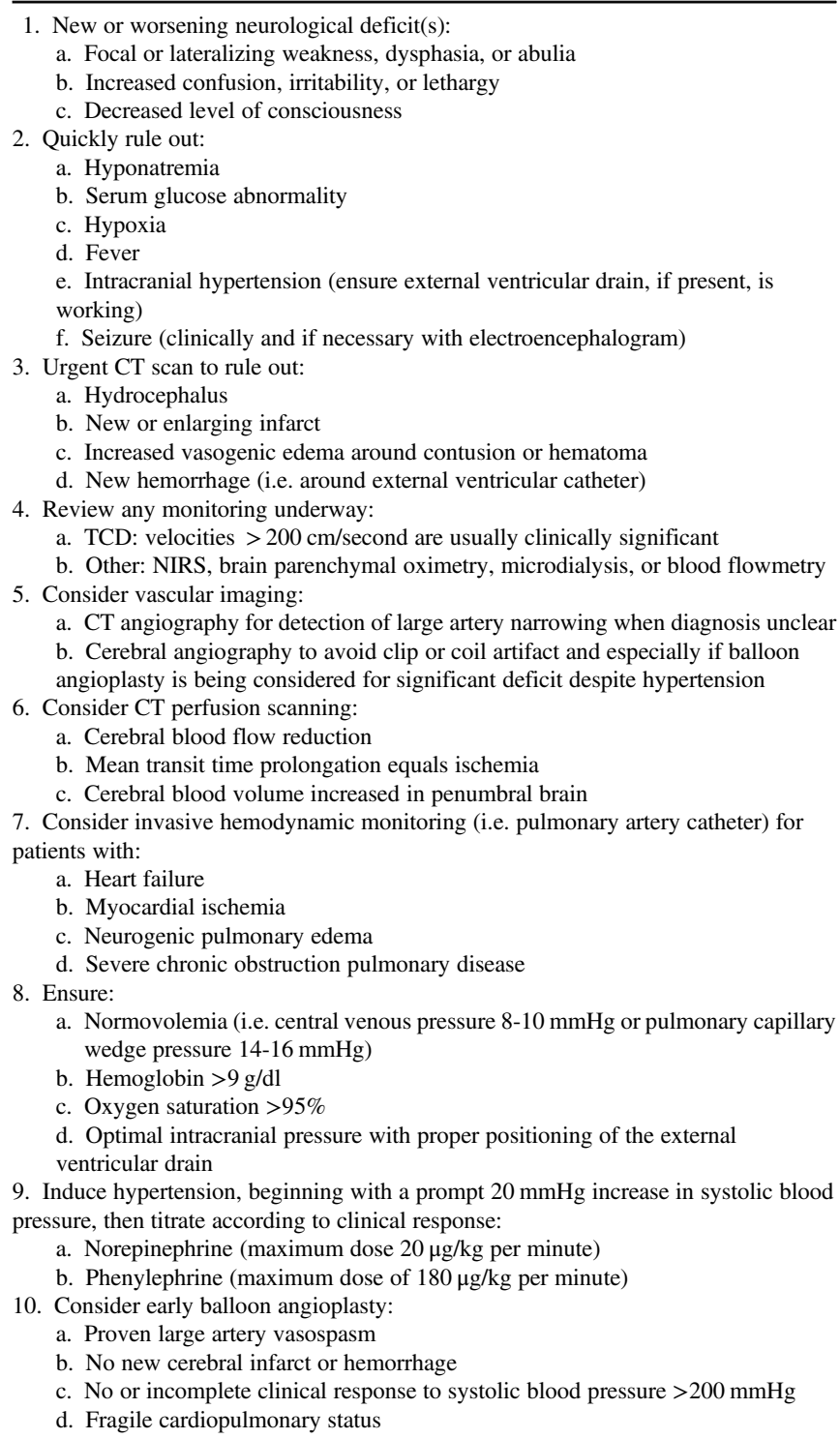

\section{Conclusion}

The most important testing for developing vasospasm and cerebral ischemia remains regular bedside neurological examinations by an experienced nurse or physician for the first two weeks following a Fisher grade 2 or higher SAH (Table 1). Transcranial Doppler is a helpful addition, bearing in mind the factors other than vasospasm that cause blood velocities to increase, making false-positive findings a hazard. Continuous monitoring of brain tissue oximetry or blood flow with a parenchymal probe or scalp patch share the drawback of surveying only a small volume of brain tissue in a single arterial territory (false-negative results therefore being a concern). CTP provides a useful and informative picture of the whole brain, but is a "snap shot in time," and like vascular imaging itself needs to be timed carefully to maximize utility (Table 5).
It is disappointing to report that recent large, randomized controlled trials did not demonstrate that the endothelin antagonist clazosentan, the cholesterol-lowering agent simvastatin, and the vasodilator magnesium sulfate prevent vasospasm, reduce delayed ischemia, or improve patient outcome following SAH. Those trials are reminders of the critical role of randomized trials in proving efficacy because all of these agents showed very promising results in preliminary studies.

The pathophysiology of vasospasm following SAH is complex and up until now has defied any simple pharmacological solution. The single and partial exception is the calcium antagonist agent nimodipine, the only treatment for cerebral vasospasm and delayed ischemia that presently achieves a class I, level of evidence "A" recommendation in the American Heart and Stroke Association aneurysmal SAH management guidelines. ${ }^{180}$ Nimodipine has been in use for nearly 30 years, but still has an uncertain mechanism of action and an overall only modest beneficial effect on outcome.

Reduction in vasospasm-related morbidity and mortality in the past two decades has been in a greater part because of appropriate fluid management following $\mathrm{SAH}$, induced hypertension when indicated for symptomatic ischemia, and judicious use of balloon angioplasty (Table 7), although these treatments will never be validated in a placebo-controlled randomized trial.

\section{ACKNOWLEDGMENTS}

The authors thank Ms. Shelan Beatty for expert assistance in preparing this review and dedicate it to our neuro- intensive care nurses who do all the hard work in looking after our patients with aneurysmal subarachnoid hemorrhage, 24/7.

\section{Disclosure InFormation}

The authors do not have anything to disclose.

\section{REFERENCES}

1. Dorsch NWC, King MT. A review of cerebral vasospasm in aneurysmal subarachnoid haemorrhage: I. Incidence and effects. J Clin Neurosci. 1994;1:19-26.

2. Fergusen S, MacDonald RL. Predictors of cerebral infarction in patients with aneurysmal subarachnoid hemorrhage. Neurosurgery. 2007;60:658-67.

3. Kassell NF, Tomer JC, Haley EC, Jr, Jane JA, Adams HP, Kongable GL. The International Cooperative Study on the Timing of Aneurysm Surgery: I. Overall management results. J Neurosurg. 1990;73:18-36.

4. Broderick JP, Brott TG, Duldner JE, Tomsick T, Leach A. Initial and recurrent bleeding are the major causes of death following subarachnoid hemorrhage. Stroke. 1994;25:1342-7.

5. Proust F, Hannequin D, Langlois O, Freger P, Crissard P. Causes of morbidity and mortality after ruptured aneurysm surgery in a series of 230 patients: the importance of control angiography. Stroke. 1995;26:1553-7.

6. Friedman JA, Goerss SJ, Meyer FB, et al. Volumetric quantification of Fisher grade 3 aneurysmal subarachnoid hemorrhage: a novel method to predict symptomatic vasospasm on admission computerized tomography scans. J Neurosurg. 2002;97:401-7.

7. Reilly C, Amidei C, Tolentino J, Jahromi BS, MacDonald RL. Clot volume and clearance rate as independent predictors of vasospasm after aneurysmal subarachnoid hemorrhage. J Neurosurg. 2004;101:255-61.

8. Kramer AH, Hehir M, Nathan B, et al. A comparison of 3 radiographic scales for the prediction of delayed ischemia and 
prognosis following subarachnoid hemorrhage. J Neurosurg. 2008;109:199-07.

9. Harrod CG, Bendok BR, Batjer HH. Prediction of cerebral vasospasm in patients presenting with aneurysmal subarachnoid hemorrhage: a review. Neurosurgery. 2005;56:633-54.

10. de Rooij N, Rinkel G, Danbaar J, Frijins CJ. Delayed cerebral ischemia after subarachnoid hemorrhage: a systematic review of clinical, laboratory, and radiological predictors. Stroke. 2013;44:43-54

11. de Rooij N, Greving J, Rinkel G, Frijins CJ. Early prediction of delayed cerebral ischemia after subarachnoid hemorrhage: development and validation of a practical risk chart. Stroke. 2013;44(5):1288-94.

12. Inagawa $\mathrm{T}$, Yahara $\mathrm{K}$, Ohbayashi N. Risk factors associated with cerebral vasospam following aneurysmal subarachnoid hemorrhage. Neurol Med Chir. 2014;54(6):465-73.

13. Abla A, Wilson D, Williamson R, et al. The relationship between ruptured aneurysm location, subarachnoid hemorrhage clot thickness, and incidence of radiographic or symptomatic vasospasm in patients enrolled in a prospective randomized controlled trial. J Neurosurg. 2014;120:391-7.

14. Mocco J, Ransom ER, Komotar RJ, et al. Racial differences in cerebral vasospasm: a systematic review of the literature. Neurosurgery. 2006;58:305-14.

15. Conway JE, Tamargo RJ. Cocaine use is an independent risk factor for cerebral vasospasm after aneurysmal subarachnoid hemorrhage. Stroke. 2001;32:2338-43.

16. Schwartz TH, Solomon RA. Perimesencephalic nonaneurysmal subarachnoid hemorrhage: review of the literature. Neurosurgery. 1996;39:433-40.

17. Rabinstein AA, Pichelmann MA, Friedman JA, et al. Symptomatic vasospasm and outcomes following aneurysmal subarachnoid hemorrhage: a comparison between surgical repair and endovascular coil occlusion. J Neurosurg. 2003;98:319-25.

18. Gross B, Lai P, Frerichs K, Du R. Treatment modality and vasospasm after aneurysmal subarachnoid hemorrhage. World Neurosurg. 2014;82(6):e725-30.

19. Ibrahim G, Morgan B, Macdonald L. Patient phenotypes associated with outcomes after aneurysmal subarachnoid hemorrhage. Stroke. 2014;45:670-6.

20. Sheth S, Hausrath D, Numis A, Lawton MT, Jospehoson SA. Intraoperative rerupture during surgical treatment of aneurysmal subarachnoid hemorrhage is not associated with an increased risk of vasospasm. J Neurosurg. 2014;120:409-14.

21. Orite F, Mink S, Tan C, et al. Impaired cerebral autoregulation is associated with vasospasm and delayed cerebral ischemia in subarachnoid hemorrhage. Stroke. 2014;45:677-82.

22. Koide M, Nishizawa S, Ohta S, Yokoyama T, Namba $H$. Chronological changes of the contractile mechanism in prolonged vasospasm after subarachnoid hemorrhage: from protein kinase $\mathrm{C}$ to protein tyrosine kinase. Neurosurgery. 2002; 51:1468-76.

23. Hansen-Schwartz J, Vajkoczy P, Macdonald RL, Pluta RM, Zhang JH. Cerebral vasospasm: looking beyond vasoconstriction. Trends Pharmacol Sci. 2007;28:252-6.

24. Megyesi JF, Vollrath B, Cook DA, Chen MH, Findlay JM. Long-term effects of in vivo angioplasty in normal and vasospastic canine carotid arteries: pharmacological and morphological analyses. J Neurosurg. 1999;91:100-8.

25. Findlay JM, Weir BKA, Kanamaru K, Espinosa F. Arterial wall changes in cerebral vasospasm. Neurosurgery. 1989;25:736-46.

26. Sasaki T, Wakai S, Asano T, Watanabe T, Kirino T, Sano K. The effect of a lipid hydroperoxide of arachidonic acid on the canine basilar artery: an experimental study on cerebral vasospasm. J Neurosurg. 1981;54:357-65.

27. Kamezaki T, Yanaka K, Nagase S, Fujita K, Kato N, Nose T. Increased levels of lipid peroxides as predictive of symptomatic vasospasm and poor outcome after aneurysmal subarachnoid hemorrhage. J Neurosurg. 2002;97:1302-5.

28. Ohta T, Satoh G, Kuroiwa T. The permeability change of major cerebral arteries in experimental vasospasm. Neurosurgery. 1992;30:331-6.
29. Foley PL, Takenaka K, Kassell NF, Lee KS. Cytotoxic effects of bloody cerebrospinal fluid on cerebral endothelial cells in culture. J Neurosurg. 1994;81:87-92.

30. Iuliano BA, Pluta RM, Jung C, Oldfield EH. Endothelial dysfunction in a primate model of cerebral vasospasm. J Neurosurg. 2004;100:287-94.

31. Moon CT, Gajdusek C, London S, Mayberg MR. Expression of endothelial nitric oxide synthase after exposure to perivascular blood. Neurosurgery. 2001;48:1328-34.

32. Pluta RM, Jung CS, Harvey-White J, et al. In vitro and in vivo effects of probucol on hydrolysis of asymmetric dimethyl L-arginine and vasospasm in primates. J Neurosurg. 2005;103:731-8.

33. Tierney TS, Clatterbuck RE, Lawson C, Thai QA, Rhines LD, Tamargo RJ. Prevention and reversal of experimental posthemorrhagic vasospasm by the periadventitial administration of nitric oxide from a controlled-release polymer. Neurosurgery. 2001;49:945-53.

34. Gabikian P, Clatterbuck RE, Eberhart CG, Tyler BM, Tierney TS, Tamargo RJ. Prevention of experimental cerebral vasospasm by intracranial delivery of a nitric oxide donor from a controlledrelease polymer. Toxicity and efficacy studies in rabbits and rats. Stroke. 2002;33:2681-6.

35. Pradilla G, Thai QA, Legnani FG, et al. Delayed intracranial delivery of a nitric oxide donor from a controlled-release polymer prevents experimental cerebral vasospasm in rabbits. Neurosurgery. 2004;55:1393-400.

36. Clatterbuck RE, Gailloud P, Tierney T, Clatterbuck VM, Murphy KJ, Tamargo RJ. Controlled release of a nitric oxide donor for the prevention of delayed cerebral vasospasm following experimental subarachnoid hemorrhage in nonhuman primates. J Neurosurg. 2005; 103:745-51.

37. Santhanam AVR, Smith LA, Akiyama M, Rosales AG, Bailey KR, Katusic ZS. Role of endothelial NO synthase phosphorylation in cerebrovascular protective effect of recombinant erythropoietin during subarachnoid hemorrhage-induced cerebral vasospasm. Stroke. 2005;36:2731-7.

38. Vatter $\mathrm{H}$, Weidauer $\mathrm{S}$, Dias $\mathrm{S}$, et al. Persistence of the nitric oxide-dependent vasodilator pathway of cerebral vessels after experimental subarachnoid hemorrhage. Neurosurgery. 2007; 60:179-88.

39. Jung CS, Oldfield EH, Harvey-White J, et al. Association of an endogenous inhibitor of nitric oxide synthase with cerebral vasospasm in patients with aneurysmal subarachnoid hemorrhage. J Neurosurg. 2007;107:945-50.

40. Chow M, Dumont AS, Kassell NF. Endothelin receptor antagonists and cerebral vasospasm: an update. Neurosurgery. 2002;51: 1333-42.

41. Seifert V, Löffler BM, Zimmermann M, Stolke D. Endothelin concentrations in patients with aneurysmal subarachnoid hemorrhage: correlation with cerebral vasospasm, delayed ischemic neurological deficits, and volume of hematoma. J Neurosurg. 1995;82:55-62.

42. Juvela S. Plasma endothelin concentrations after aneurysmal subarachnoid hemorrhage. J Neurosurg. 2000;92:390-400.

43. Mascia L, Fedorko L, Stewart DJ, et al. Temporal relationship between endothelin-1 concentrations and cerebral vasospasm in patients with aneurysmal subarachnoid hemorrhage. Stroke. 2001;32:1185-90.

44. Dumont AS, Dumont RJ, Chow MM, et al. Cerebral vasospasm after subarachnoid hemorrhage: putative role of inflammation. Neurosurgery. 2003;53:123-35.

45. Sasaki T, Kasuya H, Onda H, et al. Role of p-38 mitogen-activated protein kinase on cerebral vasospasm after subarachnoid hemorrhage. Stroke. 2004;35:1466-70.

46. Bowman G, Dixit S, Bonneau RH, Chinchilli VM, Cockruft KM. Neutralizing antibody against interleukin-6 attenuates posthemorrhagic vasospasm in the rat femoral artery model. Neurosurgery. 2004;54:719-26.

47. Clatterbuck RE, Gailloud P, Ogata L, et al. Prevention of cerebral vasospasm by a humanized anti-CD11/CD18 monoclonal antibody administered after experimental subarachnoid hemorrhage in nonhuman primates. J Neurosurg. 2003;99:376-82. 
48. Pradilla G, Wang PP, Legnani RG, Frazier JL, Tamargo RJ. Prevention of vasospasm by anti-CD11/CD18 monoclonal antibody therapy following subarachnoid hemorrhage in rabbits. $\mathbf{J}$ Neurosurg. 2004;101:88-92.

49. Macdonald RL, Zhang ZD, Ono S, Komuro T. Up-regulation of parathyroid hormone receptor in cerebral arteries after subarachnoid hemorrhage in monkeys. Neurosurgery. 2002;50: 1083-93.

50. Vikman P, Beg S, Khurana T, Hansen-Schwartz J, Edvinson L. Gene expression and molecular changes in cerebral arteries following subarachnoid hemorrhage in the rat. J Neurosurg. 2006;105: 438-44.

51. Vikman P, Ansar S, Edvinsson L. Transcriptional regulation of inflammatory and extracellular matrix-regulating genes in cerebral arteries following experimental subarachnoid hemorrhage in rats. J Neurosurg. 2007;107:1015-22.

52. Mack WJ, Ducruet AF, Hickman ZL, et al. Early plasma complement C3a levels correlate with functional outcome after aneurysmal subarachnoid hemorrhage. Neurosurgery. 2007;61:255-61.

53. Mocco J, Mack WJ, Kim GH, et al. Rise in serum soluble intercellular adhesion molecule-1 levels with vasospasm following aneurysmal subarachnoid hemorrhage. J Neurosurg. 2002;97: $537-41$

54. Schoch B, Regel JP, Wichert M, Graser T, Vollbracht L, Stolke D. Analysis of intrathecal interleukin-6 as a potential predictive factor for vasospasm in subarachnoid hemorrhage. Neurosurgery. 2007;60:828-36

55. Brown R, Kumar A, Dhar R, Samson TR, Diringer MN. The relationship between delayed infarcts and angiographic vasospasm after aneurysmal subarachnoid hemorrhage. Neurosurgery. 2013;72(5):702-8

56. Etminan N, Vergouwen M, Ilodigwe D, MacDonald RL. Effect of pharmaceutical treatment on vasospasm, delayed cerebral ischemia, and clinical outcome in patients with aneurysmal subarachnoid hemorrhage: a systematic review and met-analysis. Journal of cerebral blood flow \& metabolism. 2011;31:1443-51.

57. Rowland M, Hadjipavlou G, Kelly M, Westbrook J, Pattinson KT. Delayed cerebral ischaemia after subarachnoid haemorrhage: looking beyond vasospasm. Br J Anaesth. 2012;109(3):315-29.

58. Chen S, Feng H, Sherchan $\mathrm{P}$, et al. Controversies and evolving new mechanisms in subarachnoid hemorrhage. Prog Neurobiol. 2014;115:64-91

59. Caner B, Hou J, Altay O, Fujii M, Zhang JH. Transition of research focus from vasospasm to early brain injury after subarachnoid hemorrhage. J. Neurochem. 2012;123:(Suppl. 2):12-21.

60. Sanchez-Porras R, Zheng Z, Santos E, Scholl M, Unterberg AW, Sakowitz OW. The role of spreading depolarization in subarachnoid hemorrhage. Eur J Neurol. 2013;20:1121-7.

61. Fisher CM, Roberson GH, Ojemann RG. Cerebral vasospasm with ruptured saccular aneurysm-the clinical manifestations. Neurosurgery. 1977;1:245-58.

62. Simard J, Aldrich E, Schreibman D, James RF, Polifka A, Beaty N. Low-dose intravenous heparin infusion in patients with aneurysmal subarachnoid hemorrhage: a preliminary assessment. J Neurosurg. 2013;119:1611-9.

63. Purkayastha S, Sorond F. Transcranial doppler ultrasound: Technique and application. Semin Neurol. 2012;32(4):411-20.

64. Lindegaard KF, Bakke SJ, Sorteberg W, Nakstad P, Nornes H. A non-invasive Doppler ultrasound method for the evaluation of patients with subarachnoid hemorrhage. Acta Radiol. 1986;369: 96-8.

65. Sviri GE, Ghodke B, Britz GW, et al. Transcranial Doppler grading criteria for basilar artery vasospasm. Neurosurgery. 2006;59: 360-6.

66. Vora YY, Suarez-Almazor M, Steinke DE, Martin ML, Findlay JM. Role of transcranial Doppler monitoring in the diagnosis of cerebral vasospasm after subarachnoid hemorrhage. Neurosurgery. 1999;44:1237-48.

67. Lysakowski C, Walder B, Costanza MC, Tramer MR. Transcranial Doppler versus angiography in patients with vasospasm due to a ruptured cerebral aneurysm. A systematic review. Stroke. $2001 ; 32: 2292-8$
68. Mariak Z, Krejza J, Swiercz M, Kordecki K, Lewko J. Accuracy of transcranial color Doppler ultrasonography in the diagnosis of middle cerebral artery spasm determined by receiver operating characteristic analysis. J Neurosurg. 2002;96:323-30.

69. Lam JM, Smielweski P, Czosnyka M, Pickard JD, Kirkpatrick PJ. Predicting delayed ischemic deficits after aneurysmal subarachnoid hemorrhage using a transient hyperemic response test of cerebral autoregulation. Neurosurgery. 2000;47:819-26.

70. Ratsep T, Asser T. Cerebral hemodynamic impairment after aneurysmal subarachnoid hemorrhage as evaluated using transcranial Doppler ultrasonography: relationship to delayed cerebral ischemia and clinical outcome. J Neurosurg. 2001;95:393-401.

71. Gonzalez NR, Boscardin WJ, Glenn T, Vinuela F, Martin NA. Vasospasm probability index: a combination of transcranial Doppler velocities, cerebral blood flow, and clinical risk factors to predict cerebral vasospasm after aneurysmal subarachnoid hemorrhage. J Neurosurg. 2007;107:1101-12.

72. Okada Y, Shima T, Nishida M, et al. Comparison of transcranial Doppler investigation of aneurysmal vasospasm with digital subtraction angiographic and clinical findings. Neurosurgery. 1999;45:443-50.

73. Minhas PW, Menon DK, Smielewski P, et al. Positron emission tomographic cerebral perfusion disturbances and transcranial Doppler findings among patients with neurological deterioration and subarachnoid hemorrhage. Neurosurgery. 2003;52:1017-24.

74. Egge A, Sjoholm H, Waterloo K, Solberg T, Ingebrigsten T, Romner B. Serial single-photon emission computed tomographic and transcranial Doppler measurements for evaluation of vasospasm after aneurysmal subarachnoid hemorrhage. Neurosurgery. 2005;57:237-42.

75. Hertel F, Walter C, Bettag M, Mosdorf M. Perfusion-weighted magnetic resonance imaging in patients with vasospasm: a useful new tool in the management of patients with subarachnoid hemorrhage. Neurosurgery. 2005;56:28-35.

76. Condette-Auliac S, Bracard S, Anxionnat R, et al. Vasospasm after subarachnoid hemorrhage. Interest in diffusion-weighted MR imaging. Stroke. 2001;32:1818-24.

77. Weidauer S, Lanfermann H, Raabe A, Zanella F, Seifert V, Beck J. Impairment of cerebral perfusion and infarct patterns attributable to vasospasm after aneurysmal subarachnoid hemorrhage. A prospective MRI and DSA study. Stroke. 2007;38:1831-6.

78. van der Schaaf I, Wermer MJ, van der Graaf Y, Velthuis BK, van der Kraats CL, Rinkel GJ. Prognostic value of cerebral perfusion-computed tomography in the acute stage after subarachnoid hemorrhage for the development of delayed cerebral ischemia. Stroke. 2006;37:409-13.

79. Sviri GE, Britz GW, Lewis DH, Newell DW, Zaaroon M, Cohen W. Dynamic perfusion computed tomography in the diagnosis of cerebral vasospasm. Neurosurgery. 2006;59:319-25.

80. Washington C, Zipfel G. Detection and monitoring of vasospasm and delayed cerebral ischemia: a review and assessment of the literature. Neurocrit Care. 2011;15:312-7.

81. Dankbaar J, de Rooij N, Rijsdijk M, et al. Diagnsotic threshold values of cerebral perfusion measured with computed tomography for delayed cerebral ischemia after aneurysmal subarachnoid hemorrhage. Stroke. 2010;41:1927-32.

82. Greenberg E, Gold R, Reichman M, et al. Diagnostic accuracy of CT angiography and CT perfusion for cerebral vasospasm: a meta-analysis. AMJ Neuroradiol. 2010;31(10):1853-60.

83. Vajkoczy P, Horn P, Thome C, Muc E, Schmiedek P. Regional cerebral blood flow monitoring in the diagnosis of delayed ischemia following aneurysmal subarachnoid hemorrhage. J Neurosurg. 2003;98:1227-34.

84. Mutoh L, Ishikawa T, Suzuki A, Yasui N. Continuous cardiac output and near-infrared spectroscopy monitoring to assist in management of symptomatic cerebral vasospasm after subarachnoid hemorrhage. Neurocritical Care. 2010;13(3):331-8.

85. Zweifel C, Castellini G, Czosnyka M, et al. Continuous assessment of cerebral autoregulation with near-infrared spectroscopy in adults after subarachnoid hemorrhage. Stroke. 2010;41(9): 1963-8.

86. Brawanski A, Faltermeier R, Rothoerl R, Woertgen C. Comparison of near-infrared spectroscopy and tissue Po2 time series in 
patients after severe head injury and aneurysmal subarachnoid hemorrhage. J Cereb Blood Flow Metab. 2002;22(5):605-11.

87. Yokose N, Sakatani K, Murata Y, et al. Bedside monitoring of cerebral blood oxygenation and hemodynamics after aneurysmal subarachnoid hemorrhage by quantitative time-resolved nearinfrared spectroscopy. World Neurosurg. 2010;73(5):508-13.

88. Yoshitani K, Kawaguchi M, Miura N, et al. Effects of hemoglobin concentration, skull thickness, and the area of ther cerebrospinal fluid layer on near-infrared spectroscopy measurements. Anesthesiology. 2007;106(3):458-62.

89. Unterberg AW, Sakowitz OW, Sarrafzadeh AS, Bennedorf G, Lanksch WR. Role of bedside microdialysis in the diagnosis of cerebral vasospasm following aneurysmal subarachnoid hemorrhage. J Neurosurg. 2001;94:740-9.

90. Kett-White R, Hutchinson PJ, Al-Rawi PG, Gupta AK, Pickard JD, Kirkpatrick PJ. Adverse cerebral events detected after subarachnoid hemorrhage using brain oxygen and microdialysis probes. Neurosurgery. 2002;50:1213-22.

91. Skjoth-Rasmussen J, Schulz M, Kristensen SR, Bjerre P. Delayed neurological deficits detected by an ischemic pattern in the extracellular cerebral metabolites in patients with aneurysmal subarachnoid hemorrhage. J Neurosurg. 2004;100:8-15.

92. Spiotta A, Provencio J, Rasmussen P, Manno E. Brain monitoring after subarachnoid hemorrhage: lessons learned. Neurosurgery. 2011;69:755-66.

93. Otawara Y, Ogasawara K, Ogawa A, Sasaki M, Takahashi K. Evaluation of vasospasm after subarachnoid hemorrhage by use of multislice computed tomographic angiography. Neurosurgery. 2002;51:939-43.

94. Hattingen E, Blasel S, DuMesnil R, Vatter H, Zanella Fe, Weidauer S. MR angiography in patients with subarachnoid hemorrhage: adequate to evaluate vasospasm-induced vascular narrowing. Neurosurg Rev. 2010;33:431-9.

95. Baldwin ME, Macdonald RL, Huo D, et al. Early vasospasm on admission angiography in patients with aneurysmal subarachnoid hemorrhage is a predictor for in-hospital complications and poor outcome. Stroke. 2004;35:2506-11.

96. Nakagawa A, Su CC, Sato K, Shirane R. Evaluation of changes in circulating blood volume during acute and very acute stages of subarachnoid hemorrhage: implications for the management of hypovolemia. J Neurosurg. 2002;97:268-71.

97. Lennihan L, Mayer SA, Fink ME, et al. Effect of hypervolemic therapy on cerebral blood flow after subarachnoid hemorrhage: a randomized controlled trial. Stroke. 2000;31:383-91.

98. Egge A, Waterloo K, Sjoholm H, Solberg T, Ingebristein T, Romner B. Prophylactic hyperdynamic postoperative fluid therapy after aneurysmal subarachnoid hemorrhage: a clinical, prospective, randomized, controlled study. Neurosurgery. 2001;49:593-606.

99. Treggiari MM, Walder B, Suter PM, Romand JA. Systematic review of the prevention of delayed ischemic neurological deficits with hypertension, hypervolemia, and hemodilution therapy following subarachnoid hemorrhage. J Neurosurg. 2003;98:978-84.

100. Rinkel GJE, Feigin VL, Algra A, van Gijn J. Hypervolemia in aneurysmal subarachnoid hemorrhage. Stroke. 2005;36:1104-5.

101. Suarez JI, Shannon L, Zaidat OO, et al. Effect of human albumin administration on clinical outcome and hospital cost in patients with subarachnoid hemorrhage. J Neurosurg. 2004; 100:585-90.

102. Rahman M, Friedman W. Hyponatremia in neurosurgical patients: clinical guidelines development. Neurosurgery. 2009;65:925-36.

103. McGirt MJ, Blessing R, Nimjee SM, et al. Correlation of serum brain natriuretic peptide with hyponatremia and delayed ischemic neurological deficits after subarachnoid hemorrhage. Neurosurgery. 2004;54:1369-74.

104. Zheng B, Qiui Y, Jin H, et al. A predictive value of hyponatremia for poor outcome and cerebral infarction in high-grade aneurysmal subarachnoid hemorrhage. J Neurol Neurosurg Psychiatry. 2011;82:213-7.

105. Mori T, Katayama Y, Kawamata T, Hirayama T. Improved efficiency of hypervolemic therapy with inhibition of natriuresis by fludrocortisones in patients with aneurysmal subarachnoid hemorrhage. J Neurosurg. 1999;91:947-52.
106. Smith MJ, Le Roux PD, Elliott JP, Winn HR. Blood transfusion and increased risk for vasospasm and poor outcome after subarachnoid hemorrhage. J Neurosurg. 2004;101:1-7.

107. Bailes JE, Spetzler RF, Hadley MN, Baldwin HR. Management and morbidity of poor-grade aneurysm patients. J Neurosurg. 1990;72:559-66.

108. Dorhout Mees SM, Rinkel GJE, Feigin VL, et al. Calcium antagonists for aneurysmal subarachnoid hemorrhage. Stroke. 2009;39:514-5.

109. Megyesi JF, Findlay JM, Vollrath B, Cook DA, Chen MH. In vivo angioplasty prevents the development of vasospasm in canine carotid arteries: pharmacological and morphological analyses. Stroke. 1997;28:1216-24.

110. Zwienenberg-Lee M, Hartman J, Rudisill N, et al. Effect of prophylactic transluminal balloon angioplasty on cerebral vasospasm and outcome in patients with Fisher grade III subarachnoid hemorrhage. Results of a phase II multicenter, randomized, clinical trial. Stroke. 2008;39:1759-65.

111. Amin-Hanjani S, Ogilvy CS, Barker FG 2nd. Does intracisternal thrombolysis prevent vasospasm after aneurismal subarachnoid hemorrhage? A meta-analysis. Neurosurgery. 2004;54:326-35.

112. Kawamoto S, Tsutsumi K, Yoshikawa G, et al. Effectiveness of the head-shaking method combined with cisternal irrigation with urokinase in preventing cerebral vasospasm after subarachnoid hemorrhage. J Neurosurg. 2004;100:236-43.

113. Etminan N, Beseoglu K, Eicker S, Turowski B, Steiger HJ, Hanggi D. Prospective, randomized, open-label phase II trial on concomitant intraventricular fibrinolysis and low-frequency rotation after severe subarachnoid hemorrhage. Stroke. 2013;44:2162-8.

114. Hanggi D, Liersch J, Turowski B, Yong M, Stieger HJ. The effect of lumboventricular lavage and simultaneous low-frequency head-motion therapy after severe subarachnoid hemorrhage: results of a single center prospective phase II trial. J Neurosurg. 2008;108:1192-9.

115. Klimo P Jr, Kestle JRW, MacDonald JD, Schmidt RH. Marked reduction of cerebral vasospasm with lumbar drainage of cerebrospinal fluid after subarachnoid hemorrhage. J Neurosurg. 2004;100:215-24.

116. Al-Tamimi Y, Bhargava D, Feltbower R, et al. Lumbar drainage of cerebrospinal fluid after aneurysmal subarachnoid hemorrhage: a prospective, randomized, controlled trial (LUMAS). Stroke. 2012;43:677-82.

117. Andaluz N, Zuccarello M. Fenestration of the lamina terminalis as a valuable adjunct in aneurysm surgery. Neurosurgery. 2004;55: 1050-9.

118. Kasuya H, Onda H, Sasahara A, Takashita M, Hori T. Application of nicardipine prolonged-release implants: analysis of 97 consecutive patients with acute subarachnoid hemorrhage. Neurosurgery. 2005;56:895-902.

119. Dalbasti T, Karabiyikoglu M, Ozdamar N, Oktar N, Cagli S. Efficacy of controlled-release papaverine pellets in preventing symptomatic cerebral vasospasm. J Neurosurg. 2001;95:44-50.

120. Barth M, Capelle H, Weidauer S, et al. Effect of nicardipine prolonged-release implants on cerebral vasospasm and clinical outcome after severe aneurysmal subarachnoid hemorrhage: a prospective, randomized, double-blind phase IIa study. Stroke. 2007;38:330-6

121. Veyna RS, Seyfried D, Burke DG, et al. Magnesium sulfate therapy after aneurysmal subarachnoid hemorrhage. J Neurosurg. 2002;96:510-4.

122. Stippler S, Crago E, Levy EI, et al. Magnesium infusion for vasospasm prophylaxis after subarachnoid hemorrhage. J Neurosurg. 2006;105:723-9.

123. Schmid-Elsaesser R, Kunz M, Zausinger S, Prueckner S, Briegel J, Stieger HJ. Intravenous magnesium versus nimodipine in the treatment of patients with aneurysmal subarachnoid hemorrhage: a randomized study. Neurosurgery. 2006;58: 1054-1065.

124. Wong G, Chan M, Boet R, Poon WS, Gin T. Intravenous magnesium sulfate after aneurysmal subarachnoid hemorrhage: a prospective randomized pilot study. J Neurosurg Anethesiol. 2006;18(2):142-8. 
125. Mees S, Algra A, Vendertop W, et al. Magnesium for aneurysmal subarachnoid hemorrhage (MASH-2): a randomized placebocontrolled trial. Lancet. 2012;380(9836):44-9.

126. Golan E, Vasquez D, Ferguson N, Adhikari NK, Scales DC. Prophylactic magnesium for improving neurologic outcome after aneurysmal subarachnoid hemorrhage: systematic review and meta-analysis. Journal of Critical Care. 2013;28:173-81.

127. Shaw MDM, Vermeulen V, Murray GD, Pickard JD, Bell BA, Teasdale GM. Efficacy and safety of the endothelinA/B receptor antagonist TAK-044 in treating subarachnoid hemorrhage: a report by the Steering Committee on behalf of the IK/Netherlands/Eire TAK-044 Subarachnoid Haemorrhage Study Group. J Neurosurg. 2000;93:992-7.

128. Vajkoczy P, Meyer B, Weidauer S, et al. Clazosentan (AXV-034343), a selective endothelin A receptor antagonist, in the prevention of cerebral vasospasm following severe aneurysmal subarachnoid hemorrhage; results of a randomized, double-blind, placebo-controlled, multicenter phase IIa study. J Neurosurg. 2005;103:9-17.

129. Macdonald RL, Kassell NF, Mayer S, et al. Clazosentan to overcome neurological ischemia and infarction occurring after subarachnoid hemorrhage (CONSCIOUS-1). Stroke. 2008;39: 3015-21.

130. Macdonald R, Higashida R, Keller E, et al. Clazosentan, and enodthelin receptor antagonist, in patients with aneurysmal subarachnoid hemorrhage undergoing surgical clipping: a randomized, double-blind placebo-controlled pahse 3 trial (CONSCIOUS-2). Lancet Neurol. 2011;10(7):618-25.

131. Macdonald R, Higashida R, Keller E, et al. Randomized trial of clazosentan in patients with aneurysmal subarachnoid hemorrhage undergoing endovascular coiling. Stroke. 2012;43:1463-9.

132. O'Driscoll G, Green D, Taylor R. Simvastatin, and HMGcoenzyme A reductase inhibitor, improves endothelial function within 1 month. Circulation. 1997;95:1126-31.

133. Lynch JR, Wang H, McGirt MJ, et al. Simvastatin reduces vasospasm after aneurysmal subarachnoid hemorrhage. Results of a pilot randomized clinical trial. Stroke. 2005;36:2024-6.

134. Parra A, Kreiter KT, Williams S, et al. Effect of prior statin use on functional outcome and delayed vasospasm after acute aneurysmal subarachnoid hemorrhage: a matched controlled cohort study. Neurosurgery. 2005;56(3):476-84.

135. McGirt MJ, Blessing R, Alexander MJ, et al. Risk of cerebral vasospasm after subarachnoid hemorrhage reduced by statin therapy: a multivariate analysis of an institutional experience. J Neurosurg. 2006;10:671-4.

136. Tseng MY, Czosnyka M, Richards H, Pickard JD, Kirkpatrick PJ. Effects of acute treatment with pravastatin on cerebral vasospasm, autoregulation, and delayed ischemic deficits after aneurysmal subarachnoid hemorrhage. A phase II randomized placebocontrolled trial. Stroke. 2005;36(5):1627-32.

137. Tseng MY, Hutchinson PJ, Czosnyka M, Richards H, Pickard JD, Kirkpatrick PJ. Effects of acute pravastatin treatment on intensity of rescue therapy, length of inpatient stay, and 6-month outcome in patients after aneurysmal subarachnoid hemorrhage. Stroke. 2007;38:1545-50.

138. Vergouwen M, Meijers J, Geskus R, et al. Biolgic effects of Simvastatin in patients with aneurysmal subarachnoid hemorrhage: a double-blind, placebo-controlled randomized trial. Journal of Cerebral Blood Flow \& Metabolism. 2009; 29:1444-53.

139. Sanchez-Pena P, Nouet A, Clarencon F, et al. Atorvastatin decreases computed tomography and $\mathrm{S} 100$-assessed brain ischemia after subarachnoid aneurysmal hemorrhage: a comparative study. Crit Care Med. 2012;40(2):594-602.

140. Su S, Xu W, Hai J, Wu YF, Yu F. Effects of statins-use for patient with aneurysmal subarachnoid hemorrhage: a meta-analysis of randomized controlled trials. Sci Rep. 2014;4:4573.

141. Kirkpatrick P, Turner C, Smith C, Hutchinson PJ, Murray GD, STASH Collaborators. Simvastatin in aneurysmal subarachnoid hemorrhage (STASH): a multicentre randomized phase 3 trial. Lancet Neurol. 2014;13(11):1073-4.
142. Wong GK, Chan DY, Siu DY, et al. High-dose Simvastatin for aneurysmal subarachnoid hemorrhage: multicenter randomized controlled double-blinded clinical trial. Stroke. 2015;46:382-8.

143. Dorsch NW, Kassell NF, Sinkula MS. Metaanalysis of trials of tirilazad mesylate in aneurysmal SAH. Acta Neurochir Suppl. 2001;77:233-5

144. Jost SC, Diringer MN, Zazulia AR, et al. Effect of normal saline bolus on cerebral blood flow in regions with low baseline flow in patients with vasospasm following subarachnoid hemorrhage. J Neurosurg. 2005;103:25-30.

145. Shure D. Pulmonary artery catheters-Peace at last? N Engl J Med. 2006;354:2273-4.

146. Mutoh T, Kazumata K, Ajiki M, et al. Goal-directed fluid management by bedside transpulmonary hemodynamic monitoring after subarachnoid hemorrhage. Stroke. 2007;38:3218-24.

147. Yoneda H, Nakamura T, Shirao S, et al. Multicenter prospective cohort study on volume management after subarachnoid hemorrhage. Hemodynamic changes according to severity of subarachnoid hemorrhage and cerebral vasospasm. Stroke. 2013; 44:2155-61.

148. Mutoh T, Kazumata K, Terasaka S, Taki Y, Suzuki A, Ishikawa T. Early intensive versus minimally invasive approach to postoperative hemodynamic management after subarachnoid hemorrhage. Stroke. 2014;45:1280-4.

149. Raabe A, Beck J, Keller M, Vatter H, Zimmermann M, Seifert V. Relative importance of hypertension compared with hypervolemia for increasing cerebral oxygenation in patients with cerebral vasospasm after subarachnoid hemorrhage. J Neurosurg. 2005; 103:974-81.

150. Meyer R, Deem S, Yanez N, Souter M, Lam A, Treggiari MM. Current practices of triple-h prophylaxis and therapy in patients with subarachnoid hemorrhage. Neurocrit Care. 2011;14:24-36.

151. Naidech A, Du Y, Kreiter KT, et al. Dobutamine versus milrinone after subarachnoid hemorrhage. Neurosurgery. 2005;56:21-7.

152. Hoh BL, Carter BS, Ogilvy CS. Risk of hemorrhage from unsecured, unruptured aneurysms during and after hypertensive hypervolemic therapy. Neurosurgery. 2002;50:1207-12.

153. Rosenwasser RH, Jallo JI, Getch CC, Liebman KE. Complications of Swan-Ganz catheterization for hemodynamic monitoring in patients with subarachnoid hemorrhage. Neurosurgery. 1995;37: 872-6.

154. Miller JA, Dacey RG Jr, Diringer MN. Safety of hypertensive hypervolemic therapy with phenylephrine in the treatment of delayed ischemic deficits after subarachnoid hemorrhage. Stroke. 1995;26:2260-6.

155. Amin-Hanjani S, Schwartz RB, Sathi S, Stieg PE. Hypertensive encephalopathy as a complication of hyperdynamic therapy for vasospasm: report of two cases. Neurosurgery. 1999;44:1113-6.

156. Apostolides PJ, Greene KA, Zambramski JM, Fitzgerald JW, Spetzler RF. Intra-aortic balloon pump counterpulsation in the management of concomitant cerebral vasospasm and cardiac failure after subarachnoid hemorrhage: technical case report. Neurosurgery. 1996;38:1056-60.

157. Nussbaum ES, Sebring LA, Ganz WF, Madison MT. Intra-aortic balloon counterpulsation augments cerebral blood flow in the patient with cerebral vasospasm: a xenon-enhanced computed tomography study. Neurosurgery. 1998;42:206-14.

158. Bulters O, Birch A, Hickey E, et al. A randomized controlled trial of prophylactic intra-aorta balloon counterpulsation in high-risk aneurysmal subarachnoid hemorrhage. Stroke. 2013;44:224-6.

159. Rosenwasser RH, Armonda RA, Thomas JE, Benitez RP, Gannon PM, Harrop J. Therapeutic modalities for the management of cerebral vasospasm: timing of endovascular options. Neurosurgery. 1999, May;44(5):975-9; discussion 979-80.

160. Chalouhi N, Tjoumakaris S, Thakkar V, et al. Endovascular management of cerebral vasospasm following aneurysm rupture: outcomes and predictors in 116 patients. Clin Neurol Neurosurg. 2014;118:26-31.

161. Hoh BL, Ogilvy CS. Endovascular treatment of cerebral vasospasm: transluminal balloon angioplasty, intra-arterial papaverine, and intra-arterial nicardipine. Neurosurg Clin N Am. 2005;16(3):501-16. 
162. Megyesi JF, Vollrath B, Cook DA, Chen MH, Findlay JM. Long-term effects of in vivo angioplasty in normal and vasospastic canine carotid arteries: pharmacological and morphological analyses. J Neurosurg. 1999;91(1):100-8.

163. Megyesi JF, Findlay JM, Vollrath B, Cook DA, Chen MH. In vivo angioplasty prevents the development of vasospasm in canine carotid arteries. Pharmacological and morphological analyses. Stroke. 1997;28(6):1216-24.

164. Grande A, Nichols C, Khan U, et al. Treatment of post-hemorrhagic cerebral vasospasm: role of endovascular therapy. Acta Neurochir Suppl. 2011;110(Pt 2):127-32.

165. Higashida RT, Halbach VV, Cahan LD, et al. Transluminal angioplasty for treatment of intracranial arterial vasospasm. J Neurosurg. 1989;71(5 Pt 1):648-53.

166. Elliott JP, Newell DW, Lam DJ, et al. Comparison of balloon angioplasty and papaverine infusion for the treatment of vasospasm following aneurysmal subarachnoid hemorrhage. J Neurosurg. 1998;88(2):277-84.

167. Frontera JA, Gowda A, Grilo C, et al. Recurrent vasospasm after endovascular treatment in subarachnoid hemorrhage. Acta Neurochir Suppl. 2011;110(Pt 2):117-22.

168. Santillan A, Knopman J, Zink W, Patsalides A, Gobin YP. Transluminal balloon angioplasty for symptomatic distal vasospasm refractory to medical therapy in patients with aneurysmal subarachnoid hemorrhage. Neurosurgery. 2011;69(1):95-101; discussion 102

169. Tekle WG, Chaudry SA, Hassan AE, et al. High risk of new episode of symptomatic vasospasm in unaffected arteries in subarachnoid hemorrhage patients receiving targeted endovascular treatment for symptomatic focal vasospasm. Neurocrit Care. 2014; 20(3):399-405.

170. Fraticelli AT, Cholley BP, Losser MR, Saint Maurice JP, Payen D. Milrinone for the treatment of cerebral vasospasm after aneurysmal subarachnoid hemorrhage. Stroke. 2008;39(3):893-8.

171. Shankar JJ, dos Santos MP, Deus-Silva L, Lum C. Angiographic evaluation of the effect of intra-arterial milrinone therapy in patients with vasospasm from aneurysmal subarachnoid hemorrhage. Neuroradiology. 2011;53(2):123-8.

172. Vroom MB, Pfaffendorf M, van Wezel HB, van Zwieten PA. Effect of phosphodiesterase inhibitors on human arteries in vitro. Br J Anaesth. 1996;76:122-9.

173. Nishiguchi M, Ono S, Iseda K, Manabe H, Hishikawa T, Date I. Effect of vasodilation by milrinone, a phosphodiesterase III inhibitor, on vasospastic arteries after a subarachnoid hemorrhage in vitro and in vivo: effectiveness of cisternal injection of milrinone. Neurosurgery. 2010;66:158-64; discussion 164.

174. Khajavi K, Ayzman I, Shearer D, et al. Prevention of chronic cerebral vasospasm in dogs with milrinone. Neurosurgery. 1997;40:354-62; discussion 362-3.

175. Arakawa Y, Kikuta K, Hojo M, Goto Y, Ishii A, Yamagata S. Milrinone for the treatment of cerebral vasospasm after subarachnoid hemorrhage: report of seven cases. Neurosurgery. 2001;48:723-8; discussion 728-30.

176. Lannes M, Teitelbaum J, del Pilar Cortés M, Cardoso M, Angle M. Milrinone and homeostasis to treat cerebral vasospasm associated with subarachnoid hemorrhage: the Montreal Neurological Hospital protocol. Neurocrit Care. 2012;16(3):354-62.

177. Thomas JE, McGinnis G. Safety of intraventricular sodium nitroprusside and thiosulfate for the treatment of cerebral vasospasm in the intensive care unit setting. Stroke. 2002;33:486-92.

178. Raabe A, Zimmerman M, Setzer M, Vatter H, Berkefeld J, Seifert V. Effect of intraventricular sodium nitroprusside on cerebral hemodynamics and oxygenation in poor-grade aneurysm patients with severe, medically refractory vasospasm. Neurosurgery. 2002;50:1006-14

179. Treggiari MM, Romand JA, Martin JP, Reverdin A, Rufenacht DA, De Tribolet N. Cervical sympathetic block to reverse delayed ischemic neurological deficits after aneurysmal subarachnoid hemorrhage. Stroke. 2003;34:961-7.

180. Connolly E, Rabinstein A, Carhuapoma J, et al. Guidelines for the management of aneurysmal subarachnoid hemorrhage. A guideline for healthcare professionals from the American Heart Association/American Stroke Association. Stroke. 2012;43:1711-37. 